\title{
ANÁLISE BIBLIOMÉTRICA DOS 19 ANOS DE PUBLICAÇÕES DA REVISTA MINEIRA DE CONTABILIDADE
}

\section{BIBLIOMETRIC ANALYSIS OF PAPERS PUBLISHED IN THE JOURNAL "REVISTA MINEIRA DE CONTABILIDADE" OVER A 19-YEAR PERIOD}

\begin{abstract}
RESUMO
O presente estudo retrata o perfil das publicações da Revista Mineira de Contabilidade (RMC) no período de 2000 a 2018. Para esse fim, adotou-se a pesquisa bibliométrica para analisar os 369 artigos publicados nos 19 anos de existência do periódico. Considerando as características desses artigos, a análise foi segregada em dois períodos denominados de técnico-profissional (2000 a 2014) e técnico-científico (2015-2018). A produção do primeiro período é caracterizada: quanto às publicações - trimestrais, com predominância das linhas de Contabilidade Societária, Controladoria e Contabilidade Gerencial, e de temas relacionados à Contabilidade Financeira e Contabilidade Gerencial; quanto à autoria - realizado por um único autor, autores filiados às Instituições de Ensino Superior (IES) públicas e privadas e a órgãos de classe, que atuam profissionalmente como professores e contadores, que pertencem à região Sudeste do país, titulados ou em processo para obtenção do título de mestre e/ ou doutor, cuja formação é na área de contabilidade e controladoria. Já no segundo período, a produção é caracterizada: quanto às publicações - quadrimestrais, produções nas linhas de Contabilidade Societária e Estudos sobre ensino e Pesquisa em Contabilidade, com temas ligados à Contabilidade Financeira e à Educação Contábil; quanto à autoria - realizada em regime de parceria entre dois ou três autores, filiados majoritariamente às IES públicas que atuam profissionalmente como professores, que pertencem às regiões Sudeste, Sul e Nordeste do Brasil, cuja formação predominante é na área de contabilidade e controladoria nos níveis de mestrado e doutorado. Destaca-se que o estudo evidenciou a evolução científica do periódico, nos últimos anos, voltada a um direcionamento para maior qualidade científica e prospecção das pesquisas por ele veiculadas.
\end{abstract}

Palavras-chave: Produção Científica. Periódico único. Contabilidade.

\begin{abstract}
This study portrays the profile of publications of the journal "Revista Mineira de Contabilidade" (RMC) from 2000 to 2018. To do so, it was adopted a bibliometric research to analyze 369 papers published over 19 years. Considering the characteristics of these papers, the analysis was segregated into two periods called technical-professional (2000-2014) and technical-scientific (2015-2018). The production of the first period is characterized regarding publications - quarterly, with predominance of the lines of Corporate Accounting, Controllership and Management Accounting, and topics related to Financial Accounting, and Management Accounting; and authorship - written by a single author, affiliated with public and private HEI and professional bodies, working professionally as professors and accountants, who belong to the Southeast region of the country, who have a title or are in the process of obtaining the title of Master and/or PhD, and whose background is in Accounting and Controllership. In the second period, the production is characterized in relation to publications - quarterly, with productions in the lines of Corporate Accounting and Studies on Teaching and Research in Accounting, with topics related to Financial Accounting and Accounting Education; and to authorship - written in partnership between two or three authors, mostly affiliated to public HEIs, who act professionally as professors, who belong to the Southeast, South and Northeast regions of Brazil, and whose predominant Master o Doctorate is in the field of Accounting and Controlling. The study evidenced the scientific evolution of the journal, in recent years, to a direction for greater scientific quality and prospecting of the researches published by it.
\end{abstract}

Keywords: Scientific Production. Single journal. Accounting.

\section{Izael Oliveira Santos \\ Doutorando e Mestre em Ciências Contábeis pela Universidade Federal de Uberlândia (UFU). MBA em Gestão Financeira, Controladoria e Auditoria pela Fundação Getúlio Vargas (FGV), especialização em Direito Constitucional Aplicado pela Faculdade Damásio e em Administração Estratégica pelas Faculdades Integradas Pitágoras de Montes Claros (FIP-MOC). Graduado em Ciências Contábeis pela Universidade Estadual de Montes Claros (Unimontes) e em Direito pelas Faculdades Santo Agostinho (Fasa). Professor de Educação Superior. Contato: Rua Agnaldo Drumond, 363, apto. 203, Ibituruna, Montes Claros, MG, CEP: 39401-341. E-mail: izael. santos@ufu.br}

\section{Marise Satana de Rezende} Mestre em Ciências Contábeis pela Universidade Federal de Uberlândia (UFU). Graduada em Ciências Contábeis pela Universidade Federal de Uberlândia (UFU). Servidora Pública Municipal Contabilista na Prefeitura Municipal de Uberaba. Contato: Avenida João Naves de Avila, 2121, Santa Maria, Uberlândia, MG, CEP: 38408-100. E-mail: mariserezende@hotmail.com 


\section{INTRODUÇÃO}

Nos últimos anos, no Brasil, o campo de conhecimento da contabilidade tem apresentado um crescente desenvolvimento teórico, pois se depreende um aumento nos números de publicações na área (Abdalla et al., 2014).

A academia é o espaço apropriado para o desenvolvimento da ciência, ou seja, para a produção do conhecimento científico. A maior parcela da produção científica provém de estudos realizados nos cursos de pós-graduação. São trabalhos que procuram evidenciar diversos assuntos correlatos ao conhecimento, destacando-se os temas emergentes em cada época (SILVA, OLIVEIRA; RIBEIRO FILHO, 2005). A função primordial da produção do conhecimento na área da contabilidade, inserida nesse contexto mais amplo, deve ser a de servir de referência para os estudiosos e profissionais da área (LEITE FILHO, 2008).

Nos cursos de mestrado e doutorado, os estudantes e os pesquisadores, além das teses, dissertações e relatórios gerados, ainda podem disponibilizar os resultados encontrados para a comunidade técnico-científica, especialmente com a publicação dos trabalhos no formato de artigo em periódicos de ampla relevância para a área. Nesse sentido, Volpato (2002), ao tratar sobre os aspectos da publicação científica, afirma que publicar os resultados de estudos em periódicos que são aceitos pela comunidade científica é uma das principais responsabilidades do pesquisador, para que o conhecimento seja difundido e desenvolvido.

Desde 1999, a Revista Mineira de Contabilidade (RMC), patrocinada pelo Conselho Regional de Contabilidade de Minas Gerais (CRCMG), tem sido editada com a finalidade de divulgar a produção de conhecimentos científicos, técnicos e tecnológicos na área contábil. Em seus mais de 19 anos, a RMC se destaca por sua perenidade, vitaliciedade e evolução diante de tantas e profundas transformações ocorridas na profissão e na contabilidade no Brasil e no mundo.

Considerando que a promoção do conhecimento científico de uma área acadêmica depende da forma como acontece a comunicação das ideias no seio da comunidade científica e profissional e compreendendo os periódicos científicos como instrumentos potencializadores do desenvolvimento da ciência, é clara a importância de realizar estudos sobre eles.

No Brasil, diversos autores já se dedicaram a analisar os periódicos e suas características. Alguns desses trabalhos buscaram examinar os periódicos existentes em determinados períodos (OLIVEIRA, 2002; AVELAR, BOINA, RIBEIRO; SANTOS, 2015) com o objetivo de compará-los e compreender a produção científica publicada. Em outros trabalhos, foram desenvolvidos estudos bibliométricos, nos quais se analisaram títulos únicos de revistas científicas (LEITE; SIQUEIRA, 2007; PERDIGÃO, NIYAMA; SANTANA, 2010; RIBEIRO, 2013; RIBEIRO, 2013; PORTULHAK, 2014; RIBEIRO, 2015) com o objetivo de explorar o perfil de publicação e a contribuição de cada periódico para a área.

Segundo Anyi, Zainab e Anuar (2009), quando é realizado o estudo bibliométrico de um único periódico, o resultado é um retrato que fornece insights sobre a qualidade, maturidade e produtividade da revista, bem como a orientação da pesquisa que ela apoia. Portanto, o estudo bibliométrico de um único periódico é capaz de explorar de forma mais detalhada as suas características, as pesquisas publicadas e os autores que a escolhem como meio de divulgação de seus estudos.

Compreender o perfil de um periódico estrato qualis B3, consolidado e de livre circulação, bem como as características dos estudos publicados, dos autores e das instituições envolvidas, é relevante para explorar a evolução da própria contabilidade no contexto brasileiro. Por isso, este trabalho se propõe a retratar o perfil da produção científica da Revista Mineira de Contabilidade no período de 2000 a 2018. Os objetivos específicos propostos para o estudo são: (a) descrever as principais características dos artigos publicados na RMC; (b) analisar aspectos relacionados aos autores envolvidos nas publicações; (c) identificar o perfil do periódico, a partir das características de suas publicações.

A pesquisa tem sua relevância ao possibilitar explorar a evolução da produção acadêmica da área contábil, permitindo detectar indicadores, autores mais profícuos, temas mais abordados, metodologias e as instituições de ensino que mais contribuem para a construção de conhecimento científico veiculado no periódico. Assim, os resultados desse trabalho serão úteis a todos os que têm interesse em estudos científicos desenvolvidos na área de contabilidade.

$\mathrm{O}$ trabalho apresenta-se estruturado em cinco seções. Esta primeira apresenta a introdução que contextualiza o cenário da produção científica na área contábil e o objetivo do presente estudo. A segunda seção compreende a revisão de literatura que apresenta aspectos da produção científica em contabilidade e elementos da literatura sobre estudos bibliométricos, inclusive em relação aos trabalhos desenvolvidos na área contábil. Na terceira, estão elencados os procedimentos metodológicos adotados, seguidos pela apresentação e análise dos resultados na quarta seção. Por fim, as considerações finais são apresentadas na quinta e última seção.

\section{REVISÃO DE LITERATURA}

A produção científica pode ser identificada como um dos meios que auxiliam a sociedade na consolidação do conhecimento sobre determinado tema. Para que o acesso a essas produções seja possível, compete ao pesquisador procurar meios para divulgar os resultados de suas pesquisas tanto com a comunidade científica, quanto com os demais interessados no assunto (ROZA, MACHADO; QUINTANA, 2011).

No processo de comunicação da ciência, o periódico científico atua como uma das instâncias de consagração para pesquisadores. Ao desempenhar o papel de filtro seletivo, inteirando as sanções e exigências próprias do meio científico, 
ele certifica valor às pesquisas efetuadas e as coloca no seu grau de originalidade em relação ao conhecimento já acumulado em determinada área do conhecimento (GRUSZYNSKI; GOLIN, 2006).

A pesquisa bibliométrica consiste no exame da produção de artigos em determinado campo do saber, com o uso de métodos estatísticos e matemáticos de análise (Chueke \& Amatucci, 2015), sendo especialmente utilizada para a obtenção de indicadores de produção científica. A bibliometria pode ser compreendida como forma de medição e avaliação da ciência e dos fluxos da informação (VANTI, 2002), recurso de difusão da ciência que possibilita a identificação e o mapeamento do perfil de pesquisadores e periódicos, e técnica de investigação científica utilizada para analisar a produção do conhecimento sobre determinado assunto ou para levantar dados temáticos de uma área (SILVA DE MELO, FERREIRA DA SILVA, FALK; NASCIMENTO, 2013).

A palavra "bibliometria" se tornou conhecida ao ser utilizada por Pritchard (1969) em substituição à expressão "bibliografia estatística" (FERREIRA, 2010). De acordo com Araújo (2006), a bibliometria, inicialmente, era voltada para medidas relacionadas a livros e foi se especializando em formatos bibliográficos, como os artigos de periódicos, e, depois, ocupou-se da produtividade de autores e do estudo de citações. Hoje, os estudos bibliométricos da ciência adotam a abordagem quantitativa para mapear a produção acadêmica, independente do formato de sua divulgação (SILVA DE MELO et al., 2013).

As características da análise quantitativa da pesquisa bibliométrica atribuem ao processo de construção do conhecimento menor subjetividade. A padronização de métodos objetivos é uma vantagem na medida em que facilita a mensuração e a análise dos dados coletados, bem como o detalhamento dos aspectos observados. Nesse sentido, Santos (2003, p. 29) destaca que "os dados quantitativos são calculados a partir de contagens estatísticas das publicações ou de elementos extraídos das mesmas”.

Ao revisitar a produção científica passada, os estudos bibliométricos podem contribuir para a sistematização do estado da arte (embora não forneça uma explicação para o estado da arte), identificação de lacunas e de problemas e serem investigados em pesquisas futuras (PEDRONI, GUERRAZI, SERRA; ALBANESE, 2016). A qualidade de um estudo bibliométrico está relacionada ao rigor científico com o qual ele é desenvolvido e a sua relevância. O rigor está relacionado ao desenho da pesquisa, enquanto a relevância está associada à compreensão do fenômeno e à contribuição realizada para determinada área do conhecimento (CHUEKE; AMATUCCI, 2015).

Mesmo que a bibliometria tenha surgido devido à necessidade de avaliar a produção e a comunicação científica (Ferreira, 2010) em um campo de estudo da ciência da informação, sua aplicação não se restringe a essa área do conhecimento, principalmente em virtude da sua receptividade por outras disciplinas, como a administração e a contabilidade.

Para Pedroni et al. (2016), a quantidade e a variedade de estudos bibliométricos em contabilidade por si só já destaca a importância do tema na área. Dantas, Silva, Santana e Vieira (2011) afirmam que um dos principais parâmetros para se medir a evolução de uma área de conhecimento é a divulgação da produção científica pelos canais formais de comunicação. Dessa forma, pesquisas sobre periódicos são relevantes, inclusive para a melhoria desses meios de comunicação.

Nesse estudo, a análise bibliométrica de um único periódico, a Revista Mineira de Contabilidade, tem o propósito de contribuir para a melhoria do mesmo: identificar as linhas e as áreas temáticas às quais está vocacionado, mapear seu perfil de evolução e desenvolvimento ou, ainda, direcionar para o perfil de pesquisa que apoia.

Na literatura especializada, existem diversos estudos com a aplicação da bibliometria na área da contabilidade ${ }^{1}$. Nesse sentido, Portulhak (2014, p. 405) destaca que "são diversos os tipos de pesquisa bibliométrica já desenvolvidas e publicadas no Brasil, tendo como enfoques a própria contabilidade e assuntos específicos nessa área, a produtividade dos autores, métodos de análise empregados e perfis de publicação (...)".

Esta pesquisa dá maior atenção aos estudos com os quais se assemelha, em geral, trabalhos bibliométricos que analisaram periódicos únicos da área de contabilidade e administração. Na Tabela 1, são apresentados os estudos afins localizados na literatura nacional. O trabalho mais antigo é o de Leite Filho e Siqueira (2007), que analisou a Revista Contabilidade e Finanças no período compreendido entre 1999 e 2006. Esse trabalho se tornou uma referência, sendo citado por todos que vieram depois.

Tabela 1 - Estudos sobre periódicos únicos na área de contabilidade e administração

\begin{tabular}{c|c|c|c}
\hline $\begin{array}{c}\text { Autoria } \\
\text { (ano) }\end{array}$ & Periódico & Período & Principais Resultados \\
\hline $\begin{array}{c}\text { Leite; Siqueira } \\
\text { (2007) }\end{array}$ & $\begin{array}{c}\text { Revista de } \\
\text { Contabilidade e } \\
\text { Finanças - RCF }\end{array}$ & $1999-2006$ & $\begin{array}{c}\text { Predominância de autoria de gênero masculino e da colaboração } \\
\text { entre dois autores; 76\% dos autores tiveram apenas uma } \\
\text { contribuição no periódico; indícios de endogenia com a maioria dos } \\
\text { autores filiados à USP. }\end{array}$ \\
$\begin{array}{c}\text { Perdigão; } \\
\text { Niyama; }\end{array}$ & $\begin{array}{c}\text { Contabilidade, Gestão } \\
\text { Santana (2010) }\end{array}$ & $\begin{array}{c}\text { Governança - CGG } \\
\text { Predomínio de docentes e doutores na autoria dos artigos; autoria }\end{array}$ \\
$\begin{array}{c}\text { em parceria e diversidade de origem dos autores; baixa participação } \\
\text { de autores vinculados à UnB. }\end{array}$
\end{tabular}

1 Para acessar um apanhado geral destes trabalhos consulte Portulhak (2014). 


\begin{tabular}{|c|c|c|c|}
\hline $\begin{array}{l}\text { Autoria } \\
\text { (ano) }\end{array}$ & Periódico & Período & Principais Resultados \\
\hline $\begin{array}{l}\text { Brunozi Júnior; } \\
\text { Emmendoerfer; } \\
\text { Abrantes; Klein } \\
\quad(2011)\end{array}$ & $\begin{array}{l}\text { Revista de } \\
\text { Contabilidade \& } \\
\text { Finanças - RCF }\end{array}$ & $1989-2009$ & $\begin{array}{l}\text { Concentração de autores filiados à USP, principalmente docentes } \\
\text { doutores; Finanças e Contabilidade e Ensino de Contabilidade e } \\
\text { Conhecimento foram os temas mais abordados. }\end{array}$ \\
\hline $\begin{array}{l}\text { Francisco } \\
\quad(2011)\end{array}$ & RAE-eletrônica & $2002-2010$ & $\begin{array}{c}\text { Média de autores por artigo superior a dois; o autor mais profícuo } \\
\text { publicou cinco artigos; a maioria dos artigos foi escrita por autores } \\
\text { pertencentes a uma única IES; FGV-SP, a USP e a UFRGS são } \\
\text { as instituições mais influentes; “Gestão” é a palavra-chave mais } \\
\text { frequente. }\end{array}$ \\
\hline Ribeiro (2012) & $\begin{array}{c}\text { Brazilian Business } \\
\text { Review - BBR }\end{array}$ & $2004-2011$ & $\begin{array}{l}\text { Predominância de artigos em parceria; Valcemiro Nossa, Ariovaldo } \\
\text { dos Santos e Otávio Ribeiro de Medeiros são os autores mais } \\
\text { prolíferos; USP foi a IES que mais publicou artigos; Finanças, } \\
\text { Mercado de Capitais, Marketing, Organização e Negócios e } \\
\text { Contabilidade e Auditoria foram as temáticas mais evidenciadas. }\end{array}$ \\
\hline Ribeiro (2013a) & $\begin{array}{l}\text { Revista de Educação } \\
\text { e Pesquisa em } \\
\text { Contabilidade - REPec }\end{array}$ & $2007-2012$ & $\begin{array}{c}\text { Razão de 2,9 artigos por autor; predominância de artigos com dois } \\
\text { autores; concentração de autores com apenas um artigo publicado; } \\
\text { autores mais proficuos foram Aridelmo José Campanharo Teixeira } \\
\text { e Gilberto de Andrade Martins; USP é a IES mais produtiva; } \\
\text { preeminência da abordagem quantitativa frente à qualitativa; Ensino } \\
\text { e Pesquisa, Transparência, Contabilidade Internacional, Educação } \\
\text { Contábil, Demonstrações Contábeis Financeiras, Contabilidade } \\
\text { Gerencial, História da Contabilidade, Contabilidade Governamental, } \\
\text { Mercado de Capitais e Controladoria foram os temas mais } \\
\text { abordados. }\end{array}$ \\
\hline Ribeiro (2013b) & $\begin{array}{l}\text { Revista } \\
\text { Contemporânea de } \\
\text { Contabilidade - RCC }\end{array}$ & $2004-2012$ & $\begin{array}{l}\text { Predominância de artigos em parceria; Beuren e Colauto } \\
\text { foram os autores mais proficuos; as IES UFSC e USP foram as } \\
\text { mais produtivas; Contabilidade de Custos, Ensino e Pesquisa, } \\
\text { Contabilidade Ambiental, Governança Corporativa e Desempenho } \\
\text { Organizacional foram os temas mais abordados. }\end{array}$ \\
\hline Ribeiro (2013c) & $\begin{array}{l}\text { Revista de } \\
\text { Contabilidade e } \\
\text { Organizações - RCO }\end{array}$ & $2007-2012$ & $\begin{array}{l}\text { Predominância de artigos em parceria; USP é a IES que mais publica; } \\
\text { Ensino e Pesquisa, Disclosure, Mercados Financeiros e Contabilidade } \\
\text { Internacional foram os temas mais vistos. }\end{array}$ \\
\hline $\begin{array}{l}\text { Araujo et al. } \\
\qquad(2013)\end{array}$ & $\begin{array}{l}\text { Enfoque: Reflexão } \\
\text { Contábil - ERC }\end{array}$ & $1990-2011$ & $\begin{array}{l}\text { Média de 2,1 autores por artigo; predominância de autores do gênero } \\
\text { masculino e localizados principalmente no estado sede da revista } \\
\text { (Paraná); artigos em sua maioria elaborados por mestres, doutores, } \\
\text { mestrandos, doutorandos e pós-graduados; a maioria dos autores } \\
\text { são de universidades públicas; Contabilidade Gerencial sendo a área } \\
\text { de estudos proeminente. }\end{array}$ \\
\hline $\begin{array}{l}\text { Portulhak } \\
\text { (2014) }\end{array}$ & $\begin{array}{l}\text { Revista de } \\
\text { Contabilidade e } \\
\text { Controladoria }\end{array}$ & $2009-2013$ & $\begin{array}{l}\text { Média de } 3,0 \text { autores por artigo; UFMG é a IES com a maior } \\
\text { quantidade de autorias, seguida pela UFPR, sua mantenedora, e } \\
\text { pela USP; a maioria (3/4) das autorias se concentra nas regiões } \\
\text { Sul e Sudeste; } 43 \% \text { das autorias existentes são de pesquisadores } \\
\text { que possuem como grau máximo o doutorado; Contabilidade é a } \\
\text { principal área de formação dos autores, seguida pela Administração. }\end{array}$ \\
\hline Ribeiro (2015) & $\begin{array}{c}\text { Contabilidade Vista \& } \\
\text { Revista - CVR }\end{array}$ & $2008-2012$ & $\begin{array}{l}\text { Predominância de artigos em parceria; De Luca e Peleias são os } \\
\text { autores mais profícuos; USP é a IES com maior produção de artigos; } \\
\text { Governança corporativa, mercado de capitais, ensino e pesquisa, } \\
\text { contabilidade gerencial, contabilidade internacional e gestão de } \\
\text { custos são os temas mais vistos. }\end{array}$ \\
\hline
\end{tabular}


Observa-se que dez periódicos nacionais já foram objetos de estudos anteriores e cinco deles (BBR, RCC, RCO, REPec e CVR) foram analisados por um mesmo autor: Ribeiro (2012; 2013a; 2013b; 2013c; e 2015). Entre os periódicos examinados, estão alguns com os maiores estratos qualis (A2) da área de administração e contabilidade na última avaliação da Coordenação de Aperfeiçoamento de Pessoal de Nível Superior (Capes): Contabilidade e Finanças; Contabilidade Vista e Revista; Contabilidade e Organizações; e Revista Contemporânea de Contabilidade.

Os principais resultados desses estudos demonstram a existência de características semelhantes entre os periódicos analisados: predominância de artigos em parceria; USP como a IES com maior número de autores a ela filiados; artigos elaborados, em média, por pelo menos dois autores; indícios de endogenia, com publicações, predominantemente, de autores vinculados à instituição mantenedora do periódico.

Tais estudos são importantes para o campo de conhecimento contábil, na medida em que, além de identificar as características das publicações científicas dos principais periódicos nacionais da área, também permitem o avanço dos estudos existentes e a abertura de outras discussões sobre temas pouco ou muito estudados.

\section{PROCEDIMENTOS METODOLÓGICOS}

\subsection{Caracterização da pesquisa}

A pesquisa foi delineada de acordo com a metodologia sugerida por Beuren (2008). O trabalho caracteriza-se como descritivo, uma vez que tem como finalidade a descrição das características das publicações e dos autores de artigos veiculados na RMC (GIL, 1999). Trata-se de uma pesquisa documental porque o estudo examinou artigos publicados na RMC, lançando sobre eles um novo prisma de análise (SILVA; ZUCCOLOTTO, 2013).

Como já tratado nos tópicos anteriores, o trabalho adota uma modelagem de pesquisa bibliométrica de periódico único, fundada na descrição, padronização de procedimentos e na quantificação das publicações veiculadas na RMC. A utilização de técnicas quantitativas é o ponto central do estudo bibliométrico (ARAÚJO, 2006), sugerindo uma abordagem de pesquisa quantitativa.

\subsection{Delimitação da pesquisa}

Para a realização desse estudo, foi delimitado como objeto da pesquisa a Revista Mineira de Contabilidade (RMC). O periódico, que é de caráter técnico-científico, teve seu primeiro fascículo publicado no $4^{\circ}$ trimestre do ano 2000 e apresentou como tema “O ensino da Contabilidade em Minas Gerais”. As primeiras edições apresentavam periodicidade trimestral, eram publicadas de forma impressa e editadas em formato de brochura.

Atualmente, após passar por uma reestruturação no ano de 2015, o periódico passou a ter edições quadrimestrais publicadas exclusivamente no formato online. A RMC oferece acesso livre ao seu conteúdo, disponibilizando gratuitamente o conhecimento científico ao público, e está indexada nos seguintes diretórios e bases: Atena, Citações - Google Acadêmico, DOAJ, LATINDEX, Spell e Sumários.org, e possui como órgão financiador o Conselho Regional de Contabilidade de Minas Gerais (CRCMG). Considerando os dados disponíveis na base SPELL, a revista já obteve 50.385 acessos até o início de abril de 2019, com 11.3170 downloads e 13 citações.

Após a qualificação promovida pela Capes, ela recebeu na última avaliação trienal o estrato B3, posicionando-se mais próximo dos melhores periódicos científicos editados no Brasil. O objetivo do periódico é comunicar artigos científicos, técnicos e tecnológicos inéditos nas linhas de Contabilidade Societária; Mercados Financeiro, de Crédito e de Capitais; Controladoria e Contabilidade Gerencial; Contabilidade Governamental e do Terceiro Setor e Ensino e Pesquisa em Contabilidade.

Adicionalmente, ela também abre espaço para a publicação de resenhas, casos de ensino e ensaios teóricos que possam contribuir para a divulgação de novos conhecimentos para a comunidade contábil. A missão que a RMC assume para si é a de divulgar a produção de conhecimentos científicos, técnicos e tecnológicos na área contábil. A fim de observar como se encontram as publicações desse periódico, este estudo teve o objetivo de analisar as principais características das produções científicas publicadas na RMC no período de 2000 a 2018.

\subsection{Coleta de dados}

Neste estudo, adotou-se como universo da pesquisa a totalidade das publicações científicas da RMC que compreendeu o período de 2000 a 2018. Assim, a análise alcançou os 19 anos de existência e publicação do periódico, abrangendo um total de 369 artigos e 68 edições.

O levantamento dos dados foi realizado diretamente dos arquivos eletrônicos de todas as edições dos periódicos disponíveis para consulta no sítio eletrônico <www.revista.crcmg.org.br/> e, de forma complementar, foram observadas as informações disponíveis nos currículos Lattes dos autores.

Portanto, para alcançar o objetivo proposto, foram determinadas e analisadas as seguintes variáveis (categorias): (a) linha de pesquisa; (b) área temática da publicação; (c) autoria e coautoria; (d) profissão e formação acadêmica dos autores; (e) filiação institucional; (f) localização geográfica; e (g) procedimentos metodológicos utilizados na publicação. 
As informações úteis ao estudo foram coletadas a partir do exame individual de cada um dos artigos. Inicialmente, foi efetuada a leitura dos títulos e dos resumos de cada trabalho e, quando necessário, os demais elementos de cada um também foram examinados a fim de garantir a fidedignidade das características coletadas.

Para a avaliação dos procedimentos metodológicos dos artigos, o estudo baseou-se nos conceitos apresentados por Beuren (2008), analisando a classificação dos artigos quanto ao método, à abordagem, aos procedimentos adotados e ao modelo de coleta de dados.

Após a estruturação da base de dados, procedeu-se a padronização dos nomes dos autores, das profissões, das formações e das instituições de ensino, e, para isso, foi realizada a verificação da grafia e dos sinônimos dos nomes. Esse processo permitiu agrupar profissões e formações, mas não afastou a incidência de homônimos no caso dos autores.

Para a análise, os dados foram sumarizados e organizados em tabelas, de forma a facilitar a apresentação e discussão dos resultados. Optou-se ainda por segregar dois períodos que foram identificados como característicos dos 19 anos da RMC: o primeiro, de 2000 a 2014, como técnico-profissional e de opinião; e o segundo, de 2015 a 2018 , como técnico-científicos.

\section{APRESENTAÇÃO E DISCUSSÃO DOS RESULTADOS}

O propósito desta seção é contemplar a análise e discussão das principais características dos 369 artigos avaliados. Assim, a apresentação e discussão dos resultados foi dividida em três seções: (1) caracterização da produção científica; (2) caracterização dos autores; e (3) caracterização da metodologia utilizada nos artigos.

\subsection{Características da produção científica}

A Tabela 2 apresenta o número de fascículos, de artigos e de páginas de artigo por ano da Revista Mineira de Contabilidade e também expõe a média de artigos por fascículo e de páginas de artigo, no período de 2000 a 2018.

Com base na análise realizada, constata-se que, no primeiro ano de edição do periódico, foi disponibilizado apenas um fascículo, referente ao último trimestre de 2000. Considerando que a periodicidade estabelecida, inicialmente, foi a de publicações trimestrais, entre o ano de 2001 e 2014, apenas em 2002 observa-se uma lacuna de publicação. Em 2015, a revista sofreu uma reestruturação e passou a adotar a periodicidade quadrimestral, disponibilizando três fascículos por ano de forma eletrônica.

Tabela 2 - Distribuição dos fascículos e artigos

\begin{tabular}{|c|c|c|c|c|c|c|}
\hline Ano & $\begin{array}{c}\text { N. }^{\circ} \text { de } \\
\text { fasciculos }\end{array}$ & $\begin{array}{l}\text { N. }{ }^{\circ} \text { de } \\
\text { artigos }\end{array}$ & $\%$ & $\begin{array}{l}\text { N. }{ }^{\circ} \text { médio de } \\
\text { artigos por edição }\end{array}$ & $\begin{array}{l}\mathbf{N} .^{\circ} \text { de páginas de } \\
\text { artigo por ano }\end{array}$ & $\begin{array}{c}\mathrm{N}^{\circ} \text { médio de } \\
\text { páginas de artigo } \\
\text { por ano }\end{array}$ \\
\hline 2000 & 1 & 13 & $3,5 \%$ & 13,0 & 36 & 2,8 \\
\hline 2001 & 4 & 39 & $10,6 \%$ & 9,8 & 163 & 4,2 \\
\hline 2002 & 3 & 27 & $7,3 \%$ & 9,0 & 107 & 4,0 \\
\hline 2003 & 4 & 23 & $6,2 \%$ & 5,8 & 137 & 6,0 \\
\hline 2004 & 4 & 20 & $5,4 \%$ & 5,0 & 140 & 7,0 \\
\hline 2005 & 4 & 17 & $4,6 \%$ & 4,3 & 138 & 8,1 \\
\hline 2006 & 4 & 20 & $5,4 \%$ & 5,0 & 146 & 7,3 \\
\hline 2007 & 4 & 17 & $4,6 \%$ & 4,3 & 144 & 8,5 \\
\hline 2008 & 4 & 19 & $5,1 \%$ & 4,8 & 177 & 9,3 \\
\hline 2009 & 4 & 17 & $4,6 \%$ & 4,3 & 133 & 7,8 \\
\hline 2010 & 4 & 18 & $4,9 \%$ & 4,5 & 161 & 8,9 \\
\hline 2011 & 4 & 16 & $4,3 \%$ & 4,0 & 138 & 8,6 \\
\hline 2012 & 4 & 16 & $4,3 \%$ & 4,0 & 136 & 8,5 \\
\hline 2013 & 4 & 20 & $5,4 \%$ & 5,0 & 199 & 10,0 \\
\hline 2014 & 4 & 15 & $4,1 \%$ & 3,8 & 149 & 9,9 \\
\hline 2015 & 3 & 18 & $4,9 \%$ & 6,0 & 200 & 11,1 \\
\hline 2016 & 3 & 18 & $4,9 \%$ & 6,0 & 240 & 13,3 \\
\hline
\end{tabular}




\begin{tabular}{|c|c|c|c|c|c|c|}
\hline Ano & $\begin{array}{c}\text { N. }^{\circ} \text { de } \\
\text { fascículos }\end{array}$ & $\begin{array}{l}\text { N. }{ }^{\circ} \text { de } \\
\text { artigos }\end{array}$ & $\%$ & $\begin{array}{l}\mathbf{N} .^{\circ} \text { médio de } \\
\text { artigos por edição }\end{array}$ & $\begin{array}{l}\mathrm{N}^{\circ} \text { de páginas de } \\
\text { artigo por ano }\end{array}$ & $\begin{array}{c}\mathrm{N}^{\circ} \text { médio de } \\
\text { páginas de artigo } \\
\text { por ano }\end{array}$ \\
\hline 2017 & 3 & 18 & $4,9 \%$ & 6,0 & 224 & 12,4 \\
\hline 2018 & 3 & 18 & $4,9 \%$ & 6,0 & 219 & 12,2 \\
\hline Total & 68 & 369 & $100 \%$ & 5,4 & 2.987 & 8,1 \\
\hline
\end{tabular}

A quantidade de artigos distribuídos entre os 68 fascículos analisados apresentou uma amplitude de 26 artigos em termos de quantidade. O menor número de artigos publicados foi observado no ano 2000 , em virtude de ser o primeiro ano de edição do periódico, com apenas um fascículo. O ano seguinte, 2001, alcançou a maior quantidade de artigos observados (39 no total dos quatro fascículos publicados). No período compreendido entre 2002 e 2014, verifica-se uma pequena variação na quantidade de artigos entres os anos, obtendo-se uma média de 18,8 artigos anualmente. A partir do ano de 2015, o número de artigos se manteve constante.

Ainda, na Tabela 2, é possível verificar que a média de artigos por fascículo é de 5,4 e varia entre 3,8 artigos (mínimo) e 13,0 artigos (máximo). A quantidade máxima de artigos por fascículo é referente ao ano de 2000 e demonstra a atipicidade do primeiro ano de circulação do periódico. Observa-se que a variação da quantidade de páginas publicadas anualmente no período analisado variou entre 36 páginas (mínimo) e 240 páginas (máximo) e a menor média de páginas de artigo foi constatada no ano de 2000 (2,8 páginas por artigo). Verificou-se, ainda, que a média de páginas por artigo nos anos iniciais foram as menores observadas no período, sendo que tal fato pode estar relacionado às características dos artigos daqueles anos: artigos técnicos; comentários/ponto de vista, etc.

A análise dos 19 anos de produção científica difundida na RMC permite afirmar que houve uma nítida evolução técnico-científica dos artigos publicados no periódico. Nos anos iniciais, tinha-se a maioria de artigos curtos, em regra, de opinião ou reflexão livre sobre um tema. Com o decurso dos anos, houve um amadurecimento dos artigos apresentados e, nos últimos quatro anos, se observa a consolidação da fase científica da revista.

Essa mudança ocorreu porque o Conselho Regional de Contabilidade de Minas Gerais (CRCMG) tomou a decisão de reestruturar a revista visando a maior classificação no qualis/Capes e a ampliação da divulgação do conhecimento. Assim, todo o processo de gerenciamento da revista passou a ser feito pelo Sistema Eletrônico de Editoração de Revistas (SEER). Com isso, as regras de submissão de trabalhos foram aprimoradas, a avaliação dos textos passou a ser de forma cega e feita por pares (predominantemente por doutores em Contabilidade), as edições passaram a ser quadrimestrais e o conteúdo passou a ser disponibilizado a toda a comunidade em formato eletrônico.

A reestruturação da RMC alterou substancialmente as características das produções nela veiculadas e justifica a opção de apresentar os demais resultados pelos dois recortes temporais noticiados na metodologia, além dos resultados consolidados para o período completo. A RMC, atualmente, possui cinco linhas editorias. Para que se efetuasse a classificação de todos os 369 artigos avaliados neste trabalho, as linhas já existentes no periódico foram adotadas e foi incluída uma denominada "outras". Destaca-se que essa classificação levou em consideração as informações contidas nos artigos, especialmente aquelas presentes nos títulos e resumos.

Tabela 3 - Distribuição dos artigos por linha editorial

\begin{tabular}{c|c|c|c|c|c|c}
\hline Período: & \multicolumn{2}{|c|}{$\mathbf{2 0 0 0}$ a 2014 } & \multicolumn{2}{c|}{$\mathbf{2 0 1 5}$ a 2018 } & \multicolumn{2}{c}{$\mathbf{2 0 0 0}$ a 2018 } \\
\hline Linha Editorial & $\begin{array}{c}\text { Número de } \\
\text { publicações }\end{array}$ & $\%$ & $\begin{array}{c}\text { Número de } \\
\text { publicações }\end{array}$ & $\%$ & $\begin{array}{c}\text { Número de } \\
\text { publicações }\end{array}$ & $\%$ \\
\hline $\begin{array}{c}\text { Contabilidade Societária } \\
\text { Controladoria e Contabilidade } \\
\text { Gerencial }\end{array}$ & 120 & $40,4 \%$ & 25 & $34,7 \%$ & 145 & $39,3 \%$ \\
$\begin{array}{c}\text { Estudos sobre Ensino e Pesquisa em } \\
\text { Contabilidade }\end{array}$ & 23 & $74,9 \%$ & 8 & $11,1 \%$ & 82 & $22,2 \%$ \\
$\begin{array}{c}\text { Contabilidade Governamental e do } \\
\text { Terceiro Setor }\end{array}$ & 21 & $7,1 \%$ & 8 & $11 \%$ & 37 & $10,0 \%$ \\
$\begin{array}{c}\text { Mercados Financeiro, de Crédito e de } \\
\text { Capitais }\end{array}$ & 5 & $1,7 \%$ & 8 & $11,1 \%$ & 13 & $3,5 \%$ \\
$\quad$ Outras & 54 & $18,2 \%$ & 9 & $12,5 \%$ & 63 & $17,1 \%$ \\
Total & 297 & $100 \%$ & 72 & $100 \%$ & 369 & $100 \%$ \\
\hline
\end{tabular}


A partir da Tabela 3, é possível perceber que os artigos publicados pela RMC se concentraram na linha de Contabilidade Societária (39,3\%) e de Controladoria e Contabilidade Gerencial (22,2\%). Ainda assim, mais de 38\% dos artigos analisados ficaram distribuídos nas demais linhas. A quantidade de trabalhos na linha de Estudos sobre Ensino e Pesquisa em Contabilidade merece destaque (37 artigos), pois mostra o interesse dos pesquisadores e a abertura da revista para essa área de pesquisa.

Analisando os dois períodos da revista, observa-se que a predominância das produções na linha de Contabilidade Societária permanece. Contudo, enquanto que, de 2000 a 2014, a segunda linha em número de produções era Controladoria e Contabilidade Gerencial (24,9\%), de 2015 a 2018, a linha de Estudos sobre Ensino e Pesquisa em Contabilidade passou a ocupar essa posição, e a quantidade de trabalhos passou a representar $19,4 \%$ das publicações, bem superior aos $7,7 \%$ do período anterior. Na Tabela 4, é possível compreender melhor os assuntos centrais dos trabalhos publicados na RMC, pois eles são estratificados de acordo com as temáticas que abordam.

Tabela 4 - Distribuição dos artigos por tema

\begin{tabular}{|c|c|c|c|c|c|c|}
\hline Periodo: & \multicolumn{2}{|c|}{2000 a 2014} & \multicolumn{2}{|c|}{2015 a 2018} & \multicolumn{2}{|c|}{2000 a 2018} \\
\hline Área Temática & $\begin{array}{c}\mathbf{N}^{\circ}{ }^{\circ} \text { de } \\
\text { publicações }\end{array}$ & $\%$ & $\begin{array}{c}\mathbf{N}^{\circ}{ }^{\circ} \text { de } \\
\text { publicações }\end{array}$ & $\%$ & $\begin{array}{c}\mathbf{N}^{\circ} \text { de } \\
\text { publicações }\end{array}$ & $\%$ \\
\hline Contabilidade Financeira & 44 & $14,8 \%$ & 12 & $16,7 \%$ & 56 & $15,2 \%$ \\
\hline Contabilidade Gerencial & 43 & $14,5 \%$ & 4 & $5,6 \%$ & 47 & $12,7 \%$ \\
\hline Exercício Profissional & 36 & $12,1 \%$ & 8 & $11,1 \%$ & 44 & $11,9 \%$ \\
\hline Teoria e História da Contabilidade & 32 & $10,8 \%$ & 0 & $0,0 \%$ & 32 & $8,7 \%$ \\
\hline Contabilidade de Custos & 25 & $8,4 \%$ & 4 & $5,6 \%$ & 29 & $7,9 \%$ \\
\hline Educação Contábil & 23 & $7,7 \%$ & 12 & $16,7 \%$ & 35 & $9,5 \%$ \\
\hline $\begin{array}{c}\text { Contabilidade Internacional e } \\
\text { Comparada }\end{array}$ & 16 & $5,4 \%$ & 6 & $8,3 \%$ & 22 & $6,0 \%$ \\
\hline Contabilidade Social e Ambiental & 16 & $5,4 \%$ & 4 & $5,6 \%$ & 20 & $5,4 \%$ \\
\hline Perícia Contábil & 13 & $4,4 \%$ & 1 & $1,4 \%$ & 14 & $3,8 \%$ \\
\hline Contabilidade Pública & 12 & $4,0 \%$ & 5 & $6,9 \%$ & 17 & $4,6 \%$ \\
\hline Contabilidade Tributária & 11 & $3,7 \%$ & 3 & $4,2 \%$ & 14 & $3,8 \%$ \\
\hline Contabilidade Aplicada & 7 & $2,4 \%$ & 0 & $0,0 \%$ & 7 & $1,9 \%$ \\
\hline $\begin{array}{l}\text { Auditoria e Controladoria } \\
\text { Governamental }\end{array}$ & 6 & $2,0 \%$ & 3 & $4,2 \%$ & 9 & $2,4 \%$ \\
\hline $\begin{array}{c}\text { Controladoria, Auditoria Interna e } \\
\text { Governança }\end{array}$ & 5 & $1,7 \%$ & 0 & $0,0 \%$ & 5 & $1,4 \%$ \\
\hline Auditoria Independente & 4 & $1,3 \%$ & 3 & $4,2 \%$ & 7 & $1,9 \%$ \\
\hline Contabilidade do Terceiro Setor & 2 & $0,7 \%$ & 0 & $0,0 \%$ & 2 & $0,5 \%$ \\
\hline Contabilidade e Mercado de Capital & 2 & $0,7 \%$ & 5 & $6,9 \%$ & 7 & $1,9 \%$ \\
\hline Pesquisa Contábil & 0 & $0,0 \%$ & 2 & $2,8 \%$ & 2 & $0,5 \%$ \\
\hline Total & 297 & $100 \%$ & 72 & $100 \%$ & 369 & $100 \%$ \\
\hline
\end{tabular}

Pode-se verificar que, nos 19 anos de publicação, 15,2\% dos artigos são de temas vinculados à Contabilidade Financeira. O tema Contabilidade Gerencial é o segundo mais recorrente, com 12,7\% dos artigos totais. Nesse sentido, é possível afirmar que a dicotomia Contabilidade Societária e Controladoria e Contabilidade Gerencial, expressa na Tabela 3, é mantida aqui, em um campo mais específico, entre a Contabilidade Financeira e Gerencial. O terceiro tema mais recorrente, Exercício Profissional (11,9\%), pertence à linha editorial "outros”, e inclui trabalhos que versam sobre a atuação profissional do contador, organização e gestão de escritórios e outros temas transversais como empreendedorismo, ética, gênero, etc. Os temas Educação Contábil e Pesquisa Contábil compõem a linha de Estudos sobre Ensino e Pesquisa Contábil e verifica-se que os trabalhos nessa seara são majoritariamente sobre educação contábil (35 artigos), enquanto o tema pesquisa contábil ( 2 artigos) mostra-se incipiente nas publicações da RMC. 
No período de 2000 a 2014, os artigos vinculados ao tema de Contabilidade Financeira correspondem a 14,8\% das publicações. Ainda nesse período, o tema Contabilidade Gerencial é o segundo mais recorrente, com 14,5\% dos artigos totais, e Exercício Profissional aparece como o terceiro tema mais abordado (12,1\%). Verifica-se que os trabalhos sobre Estudos sobre Ensino e Pesquisa Contábil são exclusivamente sobre o tema Educação Contábil (23 artigos), pois não houve publicações sobre o tema Pesquisa Contábil.

Quanto às publicações relativas ao período de 2015 a 2018, verifica-se que o maior número de artigos está concentrado nos temas de Contabilidade Financeira e Educação Contábil, ambos com 16,7\% cada. Os achados corroboram os estudos de Ribeiro (2013a; 2013b; 2013c; 2015), em que o autor constata que os temas de Ensino e Pesquisa estão entre os mais abordados. Exercício Profissional continua sendo o terceiro tema mais recorrente e ressalta-se que temas como Teoria e História da Contabilidade, Contabilidade Aplicada, Controladoria, Auditora Interna e Comparada e Contabilidade do Terceiro Setor não apresentaram publicações. A análise da quantidade de autores por publicação (Tabela 5) evidencia uma concentração de artigos desenvolvidos por um único autor (44,7\%). Mais de 90\% dos artigos publicados possuíam entre 1 e 3 autores e, em apenas dois artigos, houve a constatação de seis autores.

Tabela 5 - Número de autores por publicação

\begin{tabular}{|c|c|c|c|c|c|c|}
\hline Período & \multicolumn{2}{|l|}{2000 a 2014} & \multicolumn{2}{|l|}{2015 a 2018} & \multicolumn{2}{|l|}{2000 a 2018} \\
\hline N. ${ }^{\circ}$ de autores & $\mathbf{N}^{\circ}$ de publicações & $\%$ & N. ${ }^{\circ}$ de publicações & $\%$ & N. ${ }^{\circ}$ de publicações & $\%$ \\
\hline 1 & 162 & $54,5 \%$ & 3 & $4,2 \%$ & 165 & $44,7 \%$ \\
\hline 2 & 71 & $23,9 \%$ & 20 & $27,8 \%$ & 91 & $24,7 \%$ \\
\hline 3 & 36 & $12,1 \%$ & 22 & $30,6 \%$ & 58 & $15,7 \%$ \\
\hline 4 & 20 & $6,7 \%$ & 16 & $22,2 \%$ & 36 & $9,8 \%$ \\
\hline 5 & 6 & $2,0 \%$ & 11 & $15,3 \%$ & 17 & $4,6 \%$ \\
\hline 6 & 2 & $0,7 \%$ & 0 & $0,0 \%$ & 2 & $0,5 \%$ \\
\hline Total & 297 & $100 \%$ & 72 & $100 \%$ & 369 & $100 \%$ \\
\hline
\end{tabular}

Por outro lado, se comparados os períodos 2000-2014 e 2015-2018, verifica-se que, no primeiro, há uma concentração de artigos com apenas uma autoria (54,5\%), enquanto que, no segundo período, pode-se observar uma mudança significativa, pois prevalece o regime de trabalhos em parcerias de 2 a 5 autores. O resultado para o período de 2015 a 2018 é consistente com os achados de Perdigão et al. (2010), Francisco (2011), Ribeiro (2012; 2013b; 2013c; 2015) e Portulhak (2014).

Pelos elementos até então apresentados, a produção da RMC, nestes 19 anos, é caracterizada por publicações trimestrais contendo até seis artigos (cada um com cerca de oito páginas), vinculadas às linhas de Contabilidade Societária e Controladoria e Contabilidade Gerencial, que abordam temas relacionados à Contabilidade Financeira, Contabilidade Gerencial, Exercício profissional e Educação Contábil, e realizadas por um ou dois autores.

Para o período de 2000 a 2014, o perfil mais adequado é composto por publicações trimestrais, com predominância das linhas de Contabilidade Societária, Controladoria e Contabilidade Gerencial, e de temas relacionados à Contabilidade Financeira, Contabilidade Gerencial, e trabalhos de um único autor. Enquanto isso, de 2015 a 2018 , passaram a ter destaque características como: publicações quadrimestrais, produções nas linhas Contabilidade Societária e Estudos sobre Ensino e Pesquisa em Contabilidade, com temas ligados à Contabilidade Financeira e à Educação Contábil, realizadas em regime de parceria entre dois ou três autores.

\subsection{Caracterização da autoria}

Nesta pesquisa, a caracterização da autoria dos artigos foi restringida à pessoa do primeiro autor. Dessa forma, todos os demais aspectos, como profissão, formação, instituição de filiação, formação, etc., têm como referência o autor principal do artigo. Na Tabela 6, destacam-se os autores com maior número de publicações na Revista Mineira de Contabilidade - RMC, no período de 2000 a 2018. 
Tabela 6 - Autores com maior número de publicações no período de 2000 a 2018

\begin{tabular}{|c|c|c|c|}
\hline Ordem & Autor & Instituição & $\begin{array}{l}\text { Número de } \\
\text { publicações }\end{array}$ \\
\hline $1^{\circ}$ & Carlos Alberto Serra Negra & Centro Universitário do Leste de Minas Gerais & 10 \\
\hline \multirow{3}{*}{$2^{\circ}$} & Júlio Cândido de Meirelles Júnior & Faculdades Integradas Vianna Júnior & 8 \\
\hline & Rodrigo Antônio Chaves da Silva & Faculdades Integradas de Caratinga & 8 \\
\hline & Antônio Lopes de Sá & Universidade do Grande Rio & 5 \\
\hline \multirow[t]{4}{*}{$3^{\circ}$} & Cleber do Carmo Antunes & Universidad del Museo Social Argentino & 5 \\
\hline & Salézio Dagostim & Universidade La Salle & 5 \\
\hline & Domingos Xavier Teixeira & $\begin{array}{l}\text { Conselho Regional de Contabilidade de Minas } \\
\text { Gerais }\end{array}$ & 4 \\
\hline & Elizabete Marinho Serra Negra & Fundação Visconde de Cairu & 4 \\
\hline \multirow[t]{4}{*}{$4^{\circ}$} & José Eustáquio Giovannini & Faculdade de Santa Luzia & 4 \\
\hline & Júlio Henrique Machado & Libertas Faculdades Integradas & 4 \\
\hline & Márcia Prímola de Faria & Pontifícia Universidade Católica de Minas Gerais & 4 \\
\hline & \multicolumn{2}{|c|}{ Total } & 61 \\
\hline
\end{tabular}

Verifica-se que, das 369 publicações identificadas, 16,5\% (61 trabalhos) estão concentradas com autores que possuem quatro trabalhos ou mais. O autor mais recorrente foi Carlos Alberto Serra Negra, do Centro Universitário Leste de Minas, que publicou 10 artigos. Destaca-se a existência de autores que indicaram o CRCMG como instituição filiada, e são, em geral, conselheiros, empregados e membros de grupos de estudo.

Essa análise não foi segregada por período, pois, entre 2015 a 2018, verificou-se um único autor com duas publicações, Thiago Bruno de Jesus Silva, da Universidade Federal da Grande Dourados, sendo que todos os outros autores apresentaram apenas uma única publicação na revista durante o período.

$\mathrm{Na}$ Tabela 7, são apresentadas as filiações institucionais dos autores na data em que publicaram trabalhos na RMC. Em regra, os resultados indicam que os autores são provenientes de diferentes e diversificadas IES e outras agremiações. No ranking geral, observa-se que as instituições que se destacaram no período de 2000 a 2014, pelo menos nas sete primeiras colocações se mantêm, com pouca ou nenhuma alteração.

Analisando, de forma segregada, as instituições com maior número de publicações no período de 2000 a 2014 , verifica-se que as oito primeiras são do estado de Minas Gerais e representaram mais de 34,4\% do total de publicações no período. Depois da UFMG, o CRCMG foi a instituição que mais publicou no período (18 artigos), o que é um indício de endogenia institucional, semelhante ao retratado nos estudos de Leite e Siqueira (2007), Brunozi Júnior, Emmendoerfer, Abrantes e Klein (2011), Ribeiro (2013b) e Ribeiro (2013c), e regional.

Tabela 7 - Distribuição de publicações por vínculo institucional

\begin{tabular}{|c|c|c|c|c|c|c|c|c|}
\hline \multicolumn{3}{|c|}{2000 a 2014} & \multicolumn{3}{|c|}{2015 a 2018} & \multicolumn{3}{|c|}{2000 a 2018} \\
\hline Vínculo & $\begin{array}{l}\text { N. }{ }^{\circ} \text { de } \\
\text { public. }\end{array}$ & $\%$ & Vínculo & $\begin{array}{l}\text { N. }{ }^{\circ} \text { de } \\
\text { public. }\end{array}$ & $\%$ & Vínculo & $\begin{array}{l}\text { N. }{ }^{\circ} \text { de } \\
\text { public. }\end{array}$ & $\%$ \\
\hline UFMG & 20 & $6,7 \%$ & UFSC & 5 & $6,9 \%$ & UFMG & 21 & $5,7 \%$ \\
\hline CRCMG & 18 & $6,1 \%$ & UFU & 5 & $6,9 \%$ & CRCMG & 18 & $4,9 \%$ \\
\hline PUCMG & 15 & $5,1 \%$ & UFRN & 4 & $5,6 \%$ & PUCMG & 16 & $4,3 \%$ \\
\hline UNILESTE & 13 & $4,4 \%$ & FURB & 3 & $4,2 \%$ & UFU & 15 & $4,1 \%$ \\
\hline UFU & 10 & $3,4 \%$ & UFES & 3 & $4,2 \%$ & UNILESTE & 13 & $3,5 \%$ \\
\hline UNIMONTES & 10 & $3,4 \%$ & UFPE & 3 & $4,2 \%$ & UNIMONTES & 12 & $3,3 \%$ \\
\hline CUNP & 9 & $3,0 \%$ & UFRJ & 3 & $4,2 \%$ & CUNP & 9 & $2,4 \%$ \\
\hline FUMEC & 7 & $2,4 \%$ & UnB & 3 & $4,2 \%$ & UFV & 8 & $2,2 \%$ \\
\hline FVC & 7 & $2,4 \%$ & IESP & 2 & $2,8 \%$ & UNIPAC & 8 & $2,2 \%$ \\
\hline
\end{tabular}




\begin{tabular}{|c|c|c|c|c|c|c|c|c|}
\hline \multicolumn{3}{|c|}{2000 a 2014} & \multicolumn{3}{|c|}{2015 a 2018} & \multicolumn{3}{|c|}{2000 a 2018} \\
\hline Vínculo & $\begin{array}{l}\text { N. }{ }^{\circ} \text { de } \\
\text { public. }\end{array}$ & $\%$ & Vínculo & $\begin{array}{l}\text { N. }{ }^{\circ} \text { de } \\
\text { public. }\end{array}$ & $\%$ & Vínculo & $\begin{array}{l}\text { N. }{ }^{\circ} \text { de } \\
\text { public. }\end{array}$ & $\%$ \\
\hline UNIGRANRIO & 7 & $2,4 \%$ & UEL & 2 & $2,8 \%$ & FVC & 7 & $1,9 \%$ \\
\hline UNIPAC & 7 & $2,4 \%$ & UFRPE & 2 & $2,8 \%$ & UFSC & 7 & $1,9 \%$ \\
\hline FACED & 6 & $2,0 \%$ & UFV & 2 & $2,8 \%$ & UNIGRANRIO & 7 & $1,9 \%$ \\
\hline UFV & 6 & $2,0 \%$ & UNIMONTES & 2 & $2,8 \%$ & FUMEC & 7 & $1,9 \%$ \\
\hline UFPA & 5 & $1,7 \%$ & UNIVALI & 2 & $2,8 \%$ & FACED & 6 & $1,6 \%$ \\
\hline UNIVALE & 5 & $1,7 \%$ & UNIVATES & 2 & $2,8 \%$ & UFRJ & 6 & $1,6 \%$ \\
\hline Não divulgou & 13 & $4,4 \%$ & Não divulgou & 0 & $0,0 \%$ & Não divulgou & 13 & $3,5 \%$ \\
\hline Outras & 139 & $46,8 \%$ & Outras & 29 & $40,3 \%$ & Outras & 196 & $53,1 \%$ \\
\hline Total & 297 & $100 \%$ & Total & 72 & $100 \%$ & Total & 369 & $100 \%$ \\
\hline
\end{tabular}

Ainda na Tabela 7, nota-se que, no período de 2015 a 2018, houve uma mudança em relação às instituições com maior número de publicações, não ocorrendo novamente o predomínio de instituições do estado de Minas Gerais. Assim, as instituições com o maior número de publicações são a UFSC e a UFU, ambas com 6,9\% cada, seguidas pela UFRN (5,6\%). As Instituições dos estados do Espírito Santo (UFES), Pernambuco (UFPE), Rio de Janeiro (UFRJ) e do Distrito Federal (Unb) passaram a aparecer com mais frequência, o que mostra uma mudança em relação à endogenia apresentada no período anterior.

A análise das profissões/cargos exercidos pelos autores da RMC (Tabela 8) demonstra que mais de 66\% exerciam, no momento da publicação, cargos de professor, contador ou ambos conjuntamente. Professor é a profissão mais recorrente, pois aparece isolada e associada às figuras do contador, do perito e do auditor. Destaca-se que 48,6\% dos autores exerciam alguma atividade profissional fora do ambiente de ensino, o que, de alguma forma, também direciona as publicações para uma vertente técnico-profissional.

Tabela 8 - Relação da profissão dos autores

\begin{tabular}{|c|c|c|c|c|c|c|}
\hline \multirow{2}{*}{$\begin{array}{c}\text { Período: } \\
\text { Área Temática }\end{array}$} & \multicolumn{2}{|c|}{2000 a 2014} & \multicolumn{2}{|c|}{2015 a 2018} & \multicolumn{2}{|c|}{2000 a 2018} \\
\hline & $\begin{array}{c}\text { N. } .^{\circ} \text { de } \\
\text { publicações }\end{array}$ & $\%$ & $\begin{array}{c}\mathbf{N}^{\circ}{ }^{\circ} \text { de } \\
\text { publicações }\end{array}$ & $\%$ & $\begin{array}{c}\mathrm{N}^{\circ}{ }^{\circ} \text { de } \\
\text { publicações }\end{array}$ & $\%$ \\
\hline Professor & 81 & $27,3 \%$ & 34 & $47,2 \%$ & 115 & $31,2 \%$ \\
\hline Professor/Contador & 70 & $23,6 \%$ & 0 & $0,0 \%$ & 70 & $19,0 \%$ \\
\hline Contador & 55 & $18,5 \%$ & 5 & $6,9 \%$ & 60 & $16,3 \%$ \\
\hline Estudante/Pesquisador & 30 & $10,1 \%$ & 4 & $5,6 \%$ & 34 & $9,2 \%$ \\
\hline Professor/Perito/Auditor & 17 & $5,7 \%$ & 0 & $0,0 \%$ & 17 & $4,6 \%$ \\
\hline Analista/Bancário/Consultor/Gestor & 10 & $3,4 \%$ & 3 & $4,2 \%$ & 13 & $3,5 \%$ \\
\hline Auditor/Perito & 6 & $2,0 \%$ & 2 & $2,8 \%$ & 8 & $2,2 \%$ \\
\hline Advogado & 3 & $1,0 \%$ & 0 & $0,0 \%$ & 3 & $0,8 \%$ \\
\hline Servidor Público & 2 & $0,7 \%$ & 2 & $2,8 \%$ & 4 & $1,1 \%$ \\
\hline $\begin{array}{c}\text { Assistente Contábil/de Controle/ } \\
\text { Administrativo }\end{array}$ & 2 & $0,7 \%$ & 1 & $1,4 \%$ & 3 & $0,8 \%$ \\
\hline Técnica Contábil & 1 & $0,3 \%$ & 0 & $0,0 \%$ & 1 & $0,3 \%$ \\
\hline Tutor EAD & 0 & $0,0 \%$ & 1 & $1,4 \%$ & 1 & $0,3 \%$ \\
\hline Não divulgou & 20 & $6,7 \%$ & 20 & $27,8 \%$ & 40 & $10,8 \%$ \\
\hline Total & 297 & $100 \%$ & 72 & $100 \%$ & 369 & $100 \%$ \\
\hline
\end{tabular}


Ainda na Tabela 8, há indícios de baixa participação de técnicos em contabilidade, contudo, isso é uma limitação da pesquisa, pois ainda que muitos autores tenham se declarado técnicos, quando também declararam outra profissão de nível superior, essa foi considerada, independentemente da área. A análise da Tabela 8 também indica a predominância entre os autores de profissões relacionadas às áreas afins entre as mais frequentes neste estudo, tais como administrador, economista e advogado. Outro aspecto relevante é a existência de autores com múltiplas profissões.

Ao realizar a análise dos períodos separadamente, verifica-se que, de 2000 a 2014, professor é a profissão que os autores mais exercem (27,3\%), seguidas por professor/contador $(23,6 \%)$ e contador (18,5\%). No período de 2015 a 2018 , a profissão/cargo de professor (47,2\%) continua sendo a mais recorrente e a figura do autor professor/contador não foi mais identificada nas publicações, o que pode indicar um distanciamento do exercício da docência com a identidade profissional. Destaca-se, ainda, que autores que se declararam como contadores responderam por apenas cinco publicações (6,9\%), e autores que exercem a atividade profissional fora do ambiente de ensino passaram a ser de apenas $18,1 \%$.

Para compreender a distribuição geográfica dos trabalhos, analisaram-se os estados brasileiros aos quais pertenciam os autores (Tabela 9). Ao investigar a origem das publicações, verificou-se que foram publicados trabalhos de diferentes localidades do país e vindos do exterior.

Tabela 9 - Distribuição geográfica das publicações

\begin{tabular}{|c|c|c|c|c|c|c|}
\hline \multirow{2}{*}{$\begin{array}{c}\text { Período: } \\
\text { Região }\end{array}$} & \multicolumn{2}{|c|}{2000 a 2014} & \multicolumn{2}{|c|}{2015 a 2018} & \multicolumn{2}{|c|}{2000 a 2018} \\
\hline & $\begin{array}{c}\mathrm{N}^{\circ}{ }^{\circ} \text { de } \\
\text { publicações }\end{array}$ & $\%$ & $\begin{array}{c}\mathrm{N}^{\circ}{ }^{\circ} \text { de } \\
\text { publicações }\end{array}$ & $\%$ & $\begin{array}{c}\text { N. }{ }^{\circ} \text { de } \\
\text { publicações }\end{array}$ & $\%$ \\
\hline Sudeste & 233 & $78,5 \%$ & 24 & $33,3 \%$ & 257 & $69,6 \%$ \\
\hline Sul & 24 & $8,1 \%$ & 19 & $26,4 \%$ & 43 & $11,7 \%$ \\
\hline Nordeste & 17 & $5,7 \%$ & 19 & $26,4 \%$ & 36 & $9,8 \%$ \\
\hline Centro-oeste & 5 & $1,7 \%$ & 7 & $9,7 \%$ & 12 & $3,3 \%$ \\
\hline Norte & 1 & $0,3 \%$ & 3 & $4,2 \%$ & 4 & $1,1 \%$ \\
\hline Exterior & 8 & $2,7 \%$ & 0 & $0,0 \%$ & 8 & $2,2 \%$ \\
\hline Não divulgou & 9 & $3,0 \%$ & 0 & $0,0 \%$ & 9 & $2,4 \%$ \\
\hline Total & 297 & $100 \%$ & 72 & $100 \%$ & 369 & $100 \%$ \\
\hline
\end{tabular}

No período de 2000 a 2014, é nítida a concentração de trabalhos cuja origem é a região Sudeste (78,5\%). Apenas o estado de Minas Gerais teve um total de 204 publicações no período, o que, por um lado, demonstra a circulação e uma rede de colaboração estadual do periódico, mas, que por outro, pode indicar baixo alcance e prestígio. Houve ainda publicações de origem estrangeira, dos países Portugal e Paraguai, representado 2,7\% dos artigos analisados, o que não ocorreu a partir do ano de 2015.

Ainda na Tabela 9, é possível verificar que, no período de 2015 a 2018, permanece a concentração do número de publicações provenientes da região Sudeste, porém nota-se que a representatividade diminuiu, passando a ser de 33,3\%. Um fato relevante é que, nas últimas edições, houve uma alteração na hegemonia mineira: a partir do ano de 2015, o periódico passou a ser o meio de comunicação mais utilizado por autores fora do estado de Minas, talvez em virtude da melhoria de sua qualificação junto à Capes.

Para examinar com mais detalhes o perfil dos autores que colaboraram com a RMC nos seus 19 anos de existência, foram investigadas a titulação, a área de titulação e a instituição em que cada um dos autores se titularam. Na Tabela 10 , são apresentados a titulação de cada um e o estágio de obtenção da titulação.

Considerando os dados de todo o período analisado, observa-se a predominância de autores com o título de mestre e em busca de sua obtenção (36,0\%), seguido por especialistas e pós-graduandos $(21,1 \%)$, graduados e graduandos $(20,6 \%)$ e doutores e doutorandos (15,7\%). Pode-se afirmar que mais de $50 \%$ dos autores já tinham ou estavam buscando a titulação de mestre ou doutor, de forma que o periódico se mostra como um importante veículo para divulgar as pesquisas realizadas nesses cursos, nos quais a produção científica é um dos aspectos de avaliação dos programas de pós-graduação stricto sensu. 
Tabela 10 - Titulação/estágio de formação dos autores

\begin{tabular}{|c|c|c|c|c|c|c|}
\hline \multirow{2}{*}{$\begin{array}{l}\text { Período: } \\
\text { Titulação }\end{array}$} & \multicolumn{2}{|c|}{2000 a 2014} & \multicolumn{2}{|c|}{2015 a 2018} & \multicolumn{2}{|c|}{2000 a 2018} \\
\hline & $\begin{array}{c}\text { n. }{ }^{\circ} \text { de } \\
\text { publicações }\end{array}$ & $\%$ & $\begin{array}{c}\text { n. }{ }^{\circ} \text { de } \\
\text { publicações }\end{array}$ & $\%$ & $\begin{array}{c}\text { n. }{ }^{\circ} \text { de } \\
\text { publicações }\end{array}$ & $\%$ \\
\hline Mestre & 66 & $22,2 \%$ & 19 & $26,4 \%$ & 85 & $23,0 \%$ \\
\hline Especialista & 66 & $22,2 \%$ & 5 & $6,9 \%$ & 71 & $19,2 \%$ \\
\hline Mestrando & 42 & $14,1 \%$ & 6 & $8,3 \%$ & 48 & $13,0 \%$ \\
\hline Graduado & 35 & $11,8 \%$ & 18 & $25,0 \%$ & 53 & $14,4 \%$ \\
\hline Graduando & 21 & $7,1 \%$ & 2 & $2,8 \%$ & 23 & $6,2 \%$ \\
\hline Doutor & 20 & $6,7 \%$ & 10 & $13,9 \%$ & 30 & $8,1 \%$ \\
\hline Doutorando & 17 & $5,7 \%$ & 11 & $15,3 \%$ & 28 & $7,6 \%$ \\
\hline Pós-Graduando & 7 & $2,4 \%$ & 0 & $0,0 \%$ & 7 & $1,9 \%$ \\
\hline $\mathrm{PhD}$ & 1 & $0,3 \%$ & 0 & $0,0 \%$ & 1 & $0,3 \%$ \\
\hline Tecnólogo & 1 & $0,3 \%$ & 0 & $0,0 \%$ & 1 & $0,3 \%$ \\
\hline Não divulgou & 21 & $7,1 \%$ & 1 & $1,4 \%$ & 22 & $6,0 \%$ \\
\hline Total & 297 & $100 \%$ & 72 & $100 \%$ & 369 & $100 \%$ \\
\hline
\end{tabular}

A análise por período demonstra uma evolução da qualificação dos autores colaboradores, uma vez que a participação de mestres, mestrandos, doutores e doutorandos passa de 48,8\% (2000-2014) para 63,9\% (2015-2018). A participação de graduandos e graduados como autores também evolui, o que pode ser indicativo de melhoria e incentivo à pesquisa já nesse nível de ensino. Em qualquer dos contextos, os achados corroboram os resultados do estudo de Araújo et al. (2014) de que os artigos, em sua maioria, eram elaborados por mestres, doutores, mestrandos e doutorandos.

Na Tabela 11, investigou-se a área de formação dos autores. O que se observou é que a maioria dos autores obteve titulação acadêmica (aqui analisada somente a maior) nas áreas das Ciências Contábeis e Controladoria (61,3\%), seguidas por Administração (9,2\%). Tal resultado era esperado, considerando a temática tratada pela revista, mas confirma o envolvimento de acadêmicos, docentes e profissionais da área de contabilidade e controladoria com a produção e divulgação de conhecimento em sua área de formação e atuação. Outra área de formação/titulação que podem ser destacadas são Gestão Econômica, Financeira e Empresarial (6,5\%), ainda assim, as demais áreas observadas são afins da contabilidade ou mesmo das especializações do campo contábil.

Se comparados os períodos, verifica-se que a concentração da formação em Ciências Contábeis e Controladoria passou de 57,6\% (2000-2014) para 66,4\% (2015-2018). O espaço para outras áreas e/ou especializações da contabilidade ficou mais restrito, o que não é, necessariamente, indicativo da ausência de inter/multidisciplinariedade. Pode ser apenas o efeito da maior oferta de programas de pós-graduação stricto sensu em contabilidade.

Tabela 11 - Área da formação/titulação dos autores

\begin{tabular}{|c|c|c|c|c|c|c|}
\hline Periodo: & \multicolumn{2}{|c|}{2000 a 2014} & \multicolumn{2}{|c|}{2015 a 2018} & \multicolumn{2}{|c|}{2000 a 2018} \\
\hline Área de Titulação & $\begin{array}{l}\text { Número de } \\
\text { publicações }\end{array}$ & $\%$ & $\begin{array}{l}\text { Número de } \\
\text { publicações }\end{array}$ & $\%$ & $\begin{array}{l}\text { Número de } \\
\text { publicações }\end{array}$ & $\%$ \\
\hline Ciências Contábeis & 146 & $49,2 \%$ & 45 & $62,5 \%$ & 191 & $51,8 \%$ \\
\hline Controladoria & 25 & $8,4 \%$ & 10 & $13,9 \%$ & 35 & $9,5 \%$ \\
\hline Administração & 24 & $8,1 \%$ & 10 & $13,9 \%$ & 34 & $9,2 \%$ \\
\hline $\begin{array}{c}\text { Gestão Econômica, Financeira e } \\
\text { Empresarial }\end{array}$ & 24 & $8,1 \%$ & 1 & $1,4 \%$ & 25 & $6,8 \%$ \\
\hline Ciências Empresariais e Econômicas & 9 & $3,0 \%$ & 0 & $0,0 \%$ & 9 & $2,4 \%$ \\
\hline Finanças & 9 & $3,0 \%$ & 1 & $1,4 \%$ & 10 & $2,7 \%$ \\
\hline Auditoria & 8 & $2,7 \%$ & 0 & $0,0 \%$ & 8 & $2,2 \%$ \\
\hline Engenharia de Produção & 8 & $2,7 \%$ & 0 & $0,0 \%$ & 8 & $2,2 \%$ \\
\hline
\end{tabular}




\begin{tabular}{|c|c|c|c|c|c|c|}
\hline \multirow{2}{*}{$\begin{array}{c}\text { Período: } \\
\text { Área de Titulação }\end{array}$} & \multicolumn{2}{|c|}{2000 a 2014} & \multicolumn{2}{|c|}{2015 a 2018} & \multicolumn{2}{|c|}{2000 a 2018} \\
\hline & $\begin{array}{l}\text { Número de } \\
\text { publicações }\end{array}$ & $\%$ & $\begin{array}{l}\text { Número de } \\
\text { publicações }\end{array}$ & $\%$ & $\begin{array}{l}\text { Número de } \\
\text { publicações }\end{array}$ & $\%$ \\
\hline Perícia Contábil e Consultoria & 7 & $2,4 \%$ & 1 & $1,4 \%$ & 8 & $2,2 \%$ \\
\hline Economia & 6 & $2,0 \%$ & 1 & $1,4 \%$ & 7 & $1,9 \%$ \\
\hline Ciências Jurídicas e Sociais & 4 & $1,3 \%$ & 0 & $0,0 \%$ & 4 & $1,1 \%$ \\
\hline Educação & 2 & $0,7 \%$ & 0 & $0,0 \%$ & 2 & $0,5 \%$ \\
\hline Planejamento e Governança Pública & 1 & $0,3 \%$ & 0 & $0,0 \%$ & 1 & $0,3 \%$ \\
\hline $\begin{array}{c}\text { Relações Econômicas Sociais e } \\
\text { Internacionais }\end{array}$ & 1 & $0,3 \%$ & 0 & $0,0 \%$ & 1 & $0,3 \%$ \\
\hline Ciência Florestal e Qualidade Ambiental & 1 & $0,3 \%$ & 2 & $2,8 \%$ & 3 & $0,8 \%$ \\
\hline Não divulgou & 22 & $7,4 \%$ & 1 & $1,4 \%$ & 23 & $6,2 \%$ \\
\hline Total & 297 & $100 \%$ & 72 & $100 \%$ & 369 & $100 \%$ \\
\hline
\end{tabular}

Após a análise da área de formação/titulação, buscou-se identificar as instituições nas quais os autores obtiveram ou estavam em processo de obtenção da titulação. Observou-se que os autores que publicaram na RMC, no período analisado, vinham de diversas IES públicas e privadas, de diferentes regiões do Brasil e de outros países, como Espanha, França, Inglaterra, Portugal, etc.

As instituições com maior recorrência de titulados, no período de 2000 a 2014, foram, respectivamente: Fundação Visconde de Cairu - FVC (21); Universidade Federal de Minas Gerais - UFMG (19); Fundação Getúlio Vargas - FGV (18); Pontifícia Universidade Católica de Minas Gerais - PUC MG (14); Universidade Vale do Rio Verde - Unincor (11); Universidade de São Paulo - USP (11); Universidade Federal de Uberlândia - UFU (10); Universidade Federal de Santa Catarina - UFSC (9); e Universidade Estadual de Montes Claros - Unimontes (9). Juntas, essas instituições formaram cerca de $41,1 \%$ dos autores da RMC.

Em relação ao período de 2015 a 2018, as instituições que apresentaram maior recorrência de titulados foram: Universidade Federal de Uberlândia - UFU (5); Universidade de São Paulo - USP (5); Universidade Regional de Blumenau - FURB (4); Universidade Federal de Santa Catarina - UFSC (4); UnB/UFPB/UFRN - Programa Multi-institucional e Inter-regional de Pós-graduação em Ciências Contábeis (4); Universidade Federal do Espírito Santo - UFES (3); Universidade Federal de Pernambuco - UFPE (3); Universidade Federal do Paraná - UFPR (3); Universidade Federal do Rio de Janeiro - UFRJ (3); e Universidade Federal do Rio Grande do Norte - UFRN (3), que, juntas, compreendem 51,4\% dos autores da RMC.

Em síntese, no período de 2000 a 2014, os autores da RMC são filiados, majoritariamente à UFMG, CRCMG, PUC MG, UFU, Unileste e Unimontes, atuam profissionalmente como professores e contadores, pertencem à região Sudeste, principalmente ao estado de Minas Gerais, e são ou estão estudando para se tornarem mestres e doutores, com ênfase em contabilidade e controladoria, mas com presença de diversas outras formações. No período de 2015 a 2018 , os autores são filiados à UFSC, UFU, UFRN, FURB, UFES, UFPE, UFRJ e UnB, atuam profissionalmente como professores, estão distribuídos nas regiões Sudeste, Sul e Nordeste do Brasil, cuja formação predominante é na área de contabilidade e controladoria nos níveis de mestrado e doutorado.

\subsection{Características metodológicas}

Um dos objetivos estabelecidos para o trabalho foi o de identificar as características metodológicas dos artigos publicados na RMC. Contudo, em virtude do processo evolutivo narrado anteriormente, a natureza dos artigos, principalmente no primeiro período da revista, levava a desconsideração ou pelo menos a não apresentação das características metodológicas.

Assim, mesmo com o recorte temporal, o método de pesquisa não foi identificado no corpo da maioria dos artigos investigados. Apenas 6,7\% dos trabalhos o informaram para o período de 2000 a 2014 , predominando os trabalhos empíricos e teóricos, e, para o período de 2015 a 2018, apenas $23,6 \%$ dos artigos informaram o método utilizado, predominando estudos empíricos e de caráter bibliométrico.

Ao verificar as classificações apresentadas em todos os artigos examinados, quanto aos objetivos da pesquisa desenvolvida (Tabela 12), observou-se que a maioria refere-se a estudos descritivos (17,3\%), exploratórios (7,0\%) e bibliográficos (6,5\%). Em maior ou menor proporção, essas características se mantêm nos dois períodos. A diferença mais substancial entre os períodos é o percentual de não divulgação, que retrata um pouco da estrutura de trabalhos utilizada até 2014 . 
Tabela 12 - Classificação das pesquisas

\begin{tabular}{|c|c|c|c|c|c|c|}
\hline Período: & \multicolumn{2}{|c|}{2000 a 2014} & \multicolumn{2}{|c|}{2015 a 2018} & \multicolumn{2}{|c|}{2000 a 2018} \\
\hline Classificação da Pesquisa & $\begin{array}{c}\mathbf{N} .^{\circ} \text { de } \\
\text { publicações }\end{array}$ & $\%$ & $\begin{array}{c}\mathrm{N}^{\circ}{ }^{\circ} \text { de } \\
\text { publicações }\end{array}$ & $\%$ & $\begin{array}{c}\text { N. }{ }^{\circ} \text { de } \\
\text { publicações }\end{array}$ & $\%$ \\
\hline Descritiva & 25 & $8,4 \%$ & 39 & $54,2 \%$ & 64 & $17,3 \%$ \\
\hline Exploratória & 23 & $7,7 \%$ & 3 & $4,2 \%$ & 26 & $7,0 \%$ \\
\hline Bibliográfica & 23 & $7,7 \%$ & 1 & $1,4 \%$ & 24 & $6,5 \%$ \\
\hline Exploratória/Descritiva & 3 & $1,0 \%$ & 7 & $9,7 \%$ & 10 & $2,7 \%$ \\
\hline Bibliográfica/Descritiva & 3 & $1,0 \%$ & 2 & $2,8 \%$ & 5 & $1,4 \%$ \\
\hline Documental & 4 & $1,4 \%$ & 0 & $0,0 \%$ & 4 & $1,1 \%$ \\
\hline Bibliográfica/Documental & 2 & $0,7 \%$ & 0 & $0,0 \%$ & 2 & $0,5 \%$ \\
\hline Bibliográfica/Exploratória & 2 & $0,7 \%$ & 0 & $0,0 \%$ & 2 & $0,5 \%$ \\
\hline Estudo de caso & 2 & $0,7 \%$ & 0 & $0,0 \%$ & 2 & $0,5 \%$ \\
\hline Explicativa & 0 & $0,0 \%$ & 2 & $2,8 \%$ & 2 & $0,5 \%$ \\
\hline Exploratória/Bibliográfica/Documental & 0 & $0,0 \%$ & 2 & $2,8 \%$ & 2 & $0,5 \%$ \\
\hline Bibliográfica/Exploratória/Descritiva & 1 & $0,3 \%$ & 0 & $0,0 \%$ & 1 & $0,3 \%$ \\
\hline Descritiva/Explicativa & 0 & $0,0 \%$ & 1 & $1,4 \%$ & 1 & $0,3 \%$ \\
\hline Exploratória/Explicativa & 0 & $0,0 \%$ & 1 & $1,4 \%$ & 1 & $0,3 \%$ \\
\hline Não divulgou & 209 & $70,4 \%$ & 14 & $19,4 \%$ & 223 & $60,4 \%$ \\
\hline Total & 297 & $100 \%$ & 72 & $100 \%$ & 369 & $100 \%$ \\
\hline
\end{tabular}

Na Tabela 13, estão evidenciadas as abordagens de pesquisa adotadas pelos trabalhos. Nesta classificação, apesar do alto índice $(67,8 \%)$ de artigos nos quais a aborgagem não foi indicada, houve predominância da abordagem quantitativa (13,6\%), qualitativa (12,5\%) e de ambas em conjunto (4,6\%). Proporcionalmente, tais resultados são os mesmos encontrados para os períodos de forma segregada. A única diferença observada entre os dois períodos foi a mudança da predominância da abordagem qualitativa (2000-2014) para a abordagem quantitativa (2015-2018).

Tabela 13 - Abordagem das pesquisas

\begin{tabular}{|c|c|c|c|c|c|c|}
\hline \multirow{2}{*}{$\begin{array}{c}\text { Periodo: } \\
\text { Abordagem }\end{array}$} & \multicolumn{2}{|c|}{2000 a 2014} & \multicolumn{2}{|c|}{2015 a 2018} & \multicolumn{2}{|c|}{2000 a 2018} \\
\hline & $\begin{array}{c}\mathrm{N} .^{\circ} \text { de } \\
\text { publicações }\end{array}$ & $\%$ & $\begin{array}{c}\text { N. }{ }^{\circ} \text { de } \\
\text { publicações }\end{array}$ & $\%$ & $\begin{array}{c}\text { N. }{ }^{\circ} \text { de } \\
\text { publicações }\end{array}$ & $\%$ \\
\hline Quantitativa & 18 & $6,1 \%$ & 32 & $44,4 \%$ & 50 & $13,6 \%$ \\
\hline Qualitativa & 31 & $10,4 \%$ & 15 & $20,8 \%$ & 46 & $12,5 \%$ \\
\hline Qualitativa/Quantitativa & 7 & $2,4 \%$ & 10 & $13,9 \%$ & 17 & $4,6 \%$ \\
\hline Quantitativa/Indutiva & 0 & $0,0 \%$ & 2 & $2,8 \%$ & 2 & $0,5 \%$ \\
\hline Dedutiva & 1 & $0,3 \%$ & 0 & $0,0 \%$ & 1 & $0,3 \%$ \\
\hline Lógico/Dedutiva & 1 & $0,3 \%$ & 0 & $0,0 \%$ & 1 & $0,3 \%$ \\
\hline Teórico-reflexivo & 1 & $0,3 \%$ & 0 & $0,0 \%$ & 1 & $0,3 \%$ \\
\hline Quantitativa/Dedutivo & 0 & $0,0 \%$ & 1 & $1,4 \%$ & 1 & $0,3 \%$ \\
\hline Não divulgou & 238 & $80,1 \%$ & 12 & $16,7 \%$ & 250 & $67,8 \%$ \\
\hline Total & 297 & $100 \%$ & 72 & $100 \%$ & 369 & $100 \%$ \\
\hline
\end{tabular}

A Tabela 14 apresenta os procedimentos metodológicos utilizados pelos artigos analisados. Observa-se a predominância dos procedimentos de pesquisa documental (8,4\%), levantamento ou survey (6,2\%), estudo de caso (5,4\%) e pesquisa 
bibliográfica (2,7\%). Quanto à classificação de pesquisa bibliográfica, é importante destacar que, mesmo sendo a quarta mais recorrente individualmente, ela também foi citada em 4,9\% dos artigos que indicaram mais de uma classificação.

Tabela 14 - Procedimentos metodológicos das pesquisas

\begin{tabular}{|c|c|c|c|c|c|c|}
\hline Período: & \multicolumn{2}{|c|}{2000 a 2014} & \multicolumn{2}{|c|}{2015 a 2018} & \multicolumn{2}{|c|}{2000 a 2018} \\
\hline Procedimento & $\begin{array}{l}\text { n. }{ }^{\circ} \text { de } \\
\text { public. }\end{array}$ & $\%$ & $\begin{array}{l}\text { n. }{ }^{\circ} \text { de } \\
\text { public. }\end{array}$ & $\%$ & $\begin{array}{l}\text { n. }{ }^{\circ} \text { de } \\
\text { public. }\end{array}$ & $\%$ \\
\hline Pesquisa Documental & 16 & $5,4 \%$ & 15 & $20,8 \% \%$ & 31 & $8,4 \%$ \\
\hline Levantamento/Survey & 10 & $3,4 \%$ & 13 & $18,1 \%$ & 23 & $6,2 \%$ \\
\hline Estudo de Caso & 18 & $6,1 \%$ & 2 & $2,8 \%$ & 20 & $5,4 \%$ \\
\hline Pesquisa Bibliográfica & 7 & $2,4 \%$ & 3 & $4,2 \%$ & 10 & $2,7 \%$ \\
\hline Pesquisa de campo & 7 & $2,4 \%$ & 2 & $2,8 \%$ & 9 & $2,4 \%$ \\
\hline Levantamento Bibliográfico & 4 & $1,4 \%$ & 0 & $0,0 \%$ & 4 & $1,1 \%$ \\
\hline $\begin{array}{c}\text { Pesquisa Bibliográfica/Pesquisa } \\
\text { Documental }\end{array}$ & 2 & $0,7 \%$ & 2 & $2,8 \%$ & 4 & $1,1 \%$ \\
\hline Análise de Conteúdo & 2 & $0,7 \%$ & 1 & $1,4 \%$ & 3 & $0,8 \%$ \\
\hline Estudo Multicaso & 1 & $0,3 \%$ & 2 & $2,8 \%$ & 3 & $0,8 \%$ \\
\hline Pesquisa Bibliográfica/Pesquisa de Campo & 1 & $0,3 \%$ & 2 & $2,8 \%$ & 3 & $0,8 \%$ \\
\hline Pesquisa Bibliográfica/Estudo de caso & 2 & $0,7 \%$ & 0 & $0,0 \%$ & 2 & $0,5 \%$ \\
\hline Pesquisa ex post facto & 1 & $0,3 \%$ & 1 & $1,4 \%$ & 2 & $0,5 \%$ \\
\hline $\begin{array}{l}\text { Pesquisa Bibliográfica/ } \\
\text { Análise de conteúdo }\end{array}$ & 0 & $0,0 \%$ & 2 & $2,8 \%$ & 2 & $0,5 \%$ \\
\hline Pesquisa Bibliográfica/Survey & 0 & $0,0 \%$ & 2 & $2,8 \%$ & 2 & $0,5 \%$ \\
\hline $\begin{array}{l}\text { Levantamento Bibliográfico/ } \\
\text { Estudo de caso }\end{array}$ & 1 & $0,3 \%$ & 0 & $0,0 \%$ & 1 & $0,3 \%$ \\
\hline Observação & 1 & $0,3 \%$ & 0 & $0,0 \%$ & 1 & $0,3 \%$ \\
\hline Pesquisa Bibliográfica/ex post facto & 1 & $0,3 \%$ & 0 & $0,0 \%$ & 1 & $0,3 \%$ \\
\hline Pesquisa Bibliográfica/Levantamento & 1 & $0,3 \%$ & 0 & $0,0 \%$ & 1 & $0,3 \%$ \\
\hline Pesquisa-ação & 1 & $0,3 \%$ & 0 & $0,0 \%$ & 1 & $0,3 \%$ \\
\hline $\begin{array}{l}\text { Pesquisa Bibliográfica/Pesquisa } \\
\text { Documental/Pesquisa Ex post facto }\end{array}$ & 0 & $0,0 \%$ & 1 & $1,4 \%$ & 1 & $0,3 \%$ \\
\hline Pesquisa de campo/Estudo multicaso & 0 & $0,0 \%$ & 1 & $1,4 \%$ & 1 & $0,3 \%$ \\
\hline $\begin{array}{l}\text { Pesquisa Documental/ } \\
\text { Análise de conteúdo }\end{array}$ & 0 & $0,0 \%$ & 1 & $1,4 \%$ & 1 & $0,3 \%$ \\
\hline Pesquisa Documental/Ex post facto & 0 & $0,0 \%$ & 1 & $1,4 \%$ & 1 & $0,3 \%$ \\
\hline $\begin{array}{c}\text { Pesquisa-diagnóstico/Pesquisa } \\
\text { Documental }\end{array}$ & 0 & $0,0 \%$ & 1 & $1,4 \%$ & 1 & $0,3 \%$ \\
\hline $\begin{array}{l}\text { Revisão bibliográfica/Análise } \\
\text { Documental/Pesquisa de Campo }\end{array}$ & 0 & $0,0 \%$ & 1 & $1,4 \%$ & 1 & $0,3 \%$ \\
\hline Não divulgou & 221 & $74,4 \%$ & 19 & $26,4 \%$ & 240 & $65,0 \%$ \\
\hline Total & 297 & $100 \%$ & 72 & $100 \%$ & 369 & $100 \%$ \\
\hline
\end{tabular}

Em 65\% dos artigos examinados no período de 2000 a 2018, não houve qualquer divulgação de classificação quanto aos procedimentos adotados. A comparação entre os períodos mostra que, no primeiro período, predomina a adoção de procedimentos documentais e o estudo de caso, enquanto que, no segundo, predomina a adoção de procedimentos documentais e de levantamento/survey. 
Por fim, pela análise do tipo de coleta de dados, observou-se que os artigos utilizam prioritariamente questionário $(11,4 \%)$, documental $(4,6 \%)$ e levantamento (4,6\%). Contudo, nessa classificação, o índice de não divulgação não permitiu qualquer tipo de análise mais detalhada, pois pode enviesar as interpretações. Por isso, uma pesquisa que se dedique a esse ponto pode contribuir para trazer as reais características metodológicas dos artigos publicados na revista, adotando mecanismos que classifiquem os trabalhos pelas suas características, independentemente de a classificação ser ou não indicada pelos autores.

Com base nos 19 anos de publicação, pode-se afirmar que os estudos comunicados pela RMC, quanto aos objetivos, são descritivos e exploratórios; quanto à abordagem do problema, são, em maior parte, quantitativos e adotam, prioritariamente, a pesquisa documental, de levantamento e o estudo de caso como procedimento de pesquisa, com o uso de questionários e documentos como modelagem de coleta. A estrutura metodológica dos trabalhos do último período (2015-2018) é apresentada com mais rigor, assumindo efetivamente um caráter mais científico.

\section{CONSIDERAÇÕES FINAIS}

O objetivo geral desse estudo foi analisar o perfil da produção científica da Revista Mineira de Contabilidade no período de 2000 a 2018. Para tanto, analisaram-se 369 artigos, publicados em seus 68 fascículos, durante os 19 anos de existência.

Os principais achados, considerando a análise consolidada (2000-2018), foram a predominância da linha de Contabilidade Societária, a recorrência do tema de Contabilidade Financeira, a incipiência do tema Pesquisa Contábil, a proveniência de autores de diferentes e diversificadas IES e outras agremiações localizadas, principalmente, no estado de Minas Gerais, sendo as mais profícuas a UFMG e o CRCMG. A docência foi a profissão mais recorrente, sendo que $46,9 \%$ dos autores indicaram exercer alguma atividade profissional fora do ambiente de ensino, o que, de alguma forma, também direciona as publicações para uma vertente técnico-profissional.

Ainda considerando o período consolidado, o estudo mostrou que a origem das publicações, quanto à sua localização geográfica, está concentrada na região Sudeste, e apenas o estado de Minas Gerais teve um total de 220 publicações no período - o que, por um lado, demonstra a circulação e uma rede de colaboração estadual do periódico, mas que, por outro, pode indicar baixo alcance e prestígio. É relevante destacar que, nas últimas edições, houve uma alteração na hegemonia mineira e que, a partir do ano de 2015, o periódico passou a ser o meio de comunicação mais utilizado por autores de fora do estado de Minas, talvez em virtude da melhoria de sua qualificação junto à Capes.

A análise segregada nos dois períodos (2000-2014 - produções técnico-profissionais) e (2015-2018 - produções técnico-científicas) destaca relevantes diferenças nas características assumidas pela revista desde sua reestruturação em 2015, ao mesmo tempo que demonstra a reafirmação da vocação da RMC para veicular conhecimento contábil de qualidade, acompanhando, inclusive, o desenvolvimento da contabilidade no Brasil nos últimos anos.

Portanto, essa pesquisa apresenta um retrato dos 19 anos de publicação da RMC e, como qualquer retrato, não conseguiu captar todos os ângulos do fenômeno observado. Algumas limitações, tais como ausência de padronização das informações dos currículos dos autores disponibilizados no periódico; autores sem currículo Lattes; diversidade de tipos de artigos com estruturas distintas, principalmente quando comparados os anos iniciais e finais da série temporal analisada, etc., de alguma forma, podem ter restringido o alcance das análises realizadas.

Para estudos futuros, sugere-se que sejam exploradas as características metodológicas dos artigos publicados na RMC, não pelas informações presentes nos trabalhos, mas a partir de um processo ex post de classificação, com o objetivo de verificar se os indícios da existência de duas fases do periódico (técnico-profissional e técnico-científico) são consistentes e apontar em que momento isso ocorre e quais são seus determinantes.

\section{REFERÊNCIAS}

ABDALLA, K. G. M. Z.; ROCHA, D. T.; CRUZ, J. A. W.; SANTOS, F. L. X. D.; ANDRICH, R. G.; TARDELLI, M. Pensando Contabilidade: um estudo bibliométrico e sociométrico da produção científica da Revista Pensar Contábil no Período 2006-2012. Pensar Contábil, v. 16, n. 59, p. 30-38, 2014 Disponível em: <http://www.spell.org.br/documentos/ver/31235/pensando-contabilidade--um-estudo-bibliometrico-e-sociometrico-da-producao-cientifica-da-revista-pensar-contabil-no-periodo-2006-2012/i/pt-br>.

ANYI, K. W. U.; ZAINAB, A. N.;ANUAR, N. B. Bibliometric studies on single journals: A review. Malaysian Journal of Library \& Information Science, v. 14, n. 1, p. 17-55, 2009. Disponível em: <http://ijie.um.edu.my/index.php/MJLIS/article/view/6951.

ARAÚJO, C. A. A. Bibliometria: evolução histórica e questões atuais. Em Questão, v. 12, n. 1, p. 11-32. Disponível em: <https:// dialnet.unirioja.es/servlet/articulo?codigo $=6134719>$

ARAUJO, J. D. C.; SANTANA, C. M.; ARAUJO NETO, L. M.; OLIVEIRA, D. T. Revista enfoque-reflexão contábil: uma análise das publicações. Revista Eletrônica do Alto Vale do Itajaí, v. 2, n. 1, p. 44-54, 2013 Disponível em: < http://www.revistas.udesc.br/ index.php/reavi/article/view/3443>.

AVELAR, E. A.; BOINA, T. M.; RIBEIRO, L. M. P.;SANTOS, T. S. Análise dos Artigos Publicados nos Principais Periódicos Brasileiros de Contabilidade no Século XXI. Sociedade, Contabilidade e Gestão, v. 10, n. 3, p. 63-79, 2015. Disponível em: < http://www. spell.org.br/documentoshttp://www.spell.org.br/documentos/ver/40254/analise-dos-artigos-publicados-nos-principais-periodicos-brasileiros-de-contabilidade-no-seculo-xxi/i/pt-br>. 
BEUREN, I. M. (Org.). Como elaborar trabalhos monográficos em contabilidade: Teoria e prática. 3. ed. São Paulo: Atlas, 2008.

BRUNOZI Júnior, A. C.; EMMENDOERFER, M. L.; ABRANTES, L. A.; KLEIN, T. C. Revista Contabilidade \& Finanças - USP: uma análise do perfil da produção científica de 1989 a 2009. Revista Universo Contábil, v. 7, n. 4, p. 39-59, 2011. Disponível em: http:// www.spell.org.br/documentos/ver/6322/revista-contabilidade---financas---usp--uma

analise-do-perfil-da-producao-cientifica-de-1989-a-2009/i/pt-br>.

CHUEKE, G. V.; AMATUCCI, M. O que é bibliometria? Uma introdução ao Fórum. InternexT - Revista Eletrônica de Negócios Internacionais da ESPM, v. 10, n. 2, p. 1-5, 2015. Disponível em: <http://www.spell.org.br/documentos/ver/37400/o-que-e-bibliometria--uma-introducao-ao-forum-/i/pt-br. doi: 10.18568/1980-48651021-52015>.

DANTAS, J. A.; SILVA, C. A. T.; SANTANA, C. M.; VIEIRA, E. T. Padrões de comunicação científica em contabilidade: um comparativo entre a revista contabilidade e finanças e a the accounting review. Revista Contemporânea de Contabilidade, v. 8, n. 16, p. 11-36. Disponível em: <http://www.spell.org.br/documentos/ver/35427/padroes-de-comunicacao-cientifica-em-contabilidade--um-comparativo-entre-a-revista-contabilidade-e-financas-e-a-the-accounting-review/i/pt-br. doi: 10.5007/2175-8069.2011v8n16p11>.

FERREIRA, A. G. C. Bibliometria na avaliação de periódicos científicos. Pesquisa Brasileira em Ciência da Informação e Biblioteconomia, v. 5, n. 2, 2010. Disponível em: <http://dgz.org.br/jun10/Art_05.htm>.

FRANCISCO, E. R. RAE-eletrônica: exploração do acervo à luz da bibliometria, geoanálise e redes sociais. Revista de Administração de Empresas, v. 51, n. 3, p. 280-306, 2011 Disponível em http://www.spell.org.br/documentos/ver/1883/rae-eletronica--exploracao-do-acervo-a-luz-da-bibliometria-geoanalise-e-redes-sociais/i/pt-br

GIL, A. C. Métodos e técnicas de pesquisa social. 5. ed.. São Paulo: Atlas, 1999

GRUSZYNSKI, A. C.; GOLIN, C. Periódicos científicos: Transição dos suportes impresso para o eletrônico e eficácia comunicacional. UNIrevista, v. 1, n. 3, p. 1-13, 2006. Disponível em: <https://www.researchgate.net/publication/28132173_Periodicos_Cientificos_Transicao_dos_Suportes_Impresso_para_o_Eletronico_e_Eficacia_Comunicacional>.

LEITE FILHO, G. A. Padrões de produtividade de autores em periódicos e congressos na área de contabilidade no Brasil: um estudo bibliométrico. Revista de Administração Contemporânea, v. 12, n. 2, p. 533-554, 2008. Disponível em: <http://www.spell. org.br/docu

mentos/ver/665/padroes-de-produtividade-de-autores-em-periodicos-e-congressos-na-area-de-contabilidade-no-brasil--um-estudo-bibliometrico/i/pt-br>

LEITE FILHO, G. A.; SIQUEIRA, R. L. Revista Contabilidade \& Finanças USP: Uma análise bibliométrica de 1999 a 2006. Revista de Informação Contábil, v. 1, n. 2, p. 102-119, 2007. Disponível em: < https://periodicos.ufpe.br/revistas/ricontabeis/article/ view/7736>.

OLIVEIRA, M. C. Análise dos periódicos brasileiros de contabilidade. Revista Contabilidade \& Finanças, v. 13, n. 29, p. 68-86. Disponível em: <http://www.scielo.php?script=sci_arttext\&pid=S1519-70772002000200005.doi:10.1590/S1519-70772002000200005> .

PEDRONI, F. V.; GUERRAZI, L.; SERRA, F. R.; ALBANESE, D. E. Investigación Contable, un Estudio Bibliométrico: Identificación de Publicaciones Relevantes y Examen de la Estructura Intelectual. Revista Contemporânea de Contabilidade, v. 13, n. 30, p. 53-91, 2016. Disponível em: <http://www.spell.org.br/documentos/ver/ver/44495/pesquisa-contabil--um-estudo-bibliometrico--identificacao-das-publicacoes-relevantes-e-analise-da-estrutura-intelectual/i/pt-br. doi: 10.5007/2175-8069.2016v13n30p53>.

PERDIGÃO, L. Z.; NIYAMA, J. K.; SANTANA, C. M. Contabilidade, Gestão e Governança: análise de doze anos de publicação (1998 a 2009). Contabilidade, Gestão \& Governança, v. 13, n. 3, p. 3-16, 2010. Disponível em: <<https://cgg-amg.unb.br/index. $\mathrm{php} /$ contabil/article/view/299>.

PORTULHAK, H. Revista de Contabilidade e Controladoria (RC\&C): Análise dos cinco primeiros anos de publicação (2009-2013). Revista de Educação e Pesquisa em Contabilidade (REPeC), v. 8, n. 4, p. 403-419, 2014. Disponível em: <http://www.repec.org. br/repec/article/view/1093. doi: 10.17524/repec.v8i4.1093>.

RIBEIRO, H. C. M. Brazilian Business Review: Um estudo sob a ótica da bibliometria e da rede social de 2004 a 2011. Revista de Gestão, Finanças e Contabilidade, v. 2, n. 3, p. 86-104, 2012. Disponível em: <http://www.spell.org.br/documentos/ver/37842/ brazilian-business-review--um-estudo-sob-a-otica-da-bibliometria-e-da-rede-social-de-2004-a-2011/i/pt-br>.

RIBEIRO, H. C. M. Características da produção veiculada na Revista de Educação e Pesquisa em Contabilidade no período de 2007 a 2012. Revista de Educação e Pesquisa em Contabilidade, v. 7, n. 4, p. 424-443, 2013a. Disponível em: <http://www.spell org.br/documentos/ver/18277/caracteristicas-da-producao-veiculada-na-revista-de-educacao-e-pesquisa-em-contabilidade-no-periodo-de-2007-a-2012/i/pt-br>

RIBEIRO, H. C. M. Revista Contemporânea de Contabilidade: uma análise do perfil da produção acadêmica durante o período de 2004 a 2012. Revista Contemporânea de Contabilidade, v. 10, n. 20, p. 3-28, 2013b Disponível em: $\leq$ https://periodicos.ufsc.br/ index.php/contabilidade/article/view/2175-8069.2013v10n20p3.doi:10.5007/21758069.2013.v10n20p3>.

RIBEIRO, H. C. M. Revista de Contabilidade e Organizações: uma análise bibliométrica e de redes sociais de 2007 a 2012 . Revista Iberoamericana de Contabilidad de Gestión, v. 11, n. 22, p. 1-18, 2013c. Disponível em: <www.observatorio-iberoamericano.org/ ricg $/ \mathrm{N}^{\circ}$ _22//Henrique_César_Melo.pdf>.

RIBEIRO, H. C. M. Estado da arte da Revista Contabilidade Vista \& Revista: uma análise da produção acadêmica de 2008 a 2012. Contexto - Revista do Programa de Pós-Graduação em Controladoria e Contabilidade da UFRGS, v. 15, n. 30, p. 36-56, 2015 Disponível em http://www.spell.org.br/documentos/ver/47768/estado-da-arte-da-revista-contabilidade-vista---revista--uma-analise-da-producao-academica-de-2008-a-2012/i/pt-br. 
ROZA, M. C.; MACHADO, D. G.; QUINTANA, A. C. Análise bibliométrica da produção científica sobre contabilidade pública no encontro de administração pública e governança (EnAPG) e na Revista de Administração Pública (RAP), no período 2004-2009. Contexto - Revista do Programa de Pós-Graduação em Controladoria e Contabilidade da UFRGS, v. 11, n. 20, p. 59-72, 2011. Disponível em: <http://www.spell.org.br/documento/s/ver/47684/analise-bibliometrica-da-producao-cientifica-sobre-contabilidade-publica-no-encontro-de-administracao-publica-e-governanca--enapg--e-na-revista-de-administracao-publica--rap---no-periodo-2004-2009/i/pt-br>.

SANTOS, R. N. M. Produção científica: Por que medir? O que medir? Revista Digital de Biblioteconomia e Ciência da Informação, v. 1, n. 1, p. 22-38, 2004. Disponível em: <https://periodicos.sbu.unicamp.br/ojs/index.php/rdbci/article/view/2087. doi:https://doi.org/10.20396/rdbci.v1i1.2087>.

SILVA, A. C.; OLIVEIRA, E. C.; RIBEIRO FILHO, J. F. R. Revista Contabilidade \& Finanças - USP: Uma comparação entre os períodos 1989/2001 e 2001/2004. Revista Contabilidade \& Finanças - USP, v. 39, n. 16, p. 20-32, 2005. Disponível em: <http://www. scielo.br/scielo.php?script=sci_arttext\&pid=S1519--70772005000300003.doi: 10.1590/S1519-70772005000300003.

SILVA, S. C.; ZUCCOLOTTO, R. Propriedades dos estudos de teoria da contabilidade em um periódico científico brasileiro. Enfoque: Reflexão Contábil ,v. 33, n. 2, p. 35-53, 2014. Disponível em: <http://periodicos.uem.br/ojs/index.php/Enfoque/article/ view/19747.doi: 10.4025/enfoque.v33i2.19747>.

SILVA de MELO, D. L.; FERREIRA da SILVA, A. P.; FALK, J. A.; NASCIMENTO, R. G. Controladoria: um estudo bibliométrico dos artigos publicados em periódicos avaliados pela CAPES. Revista de Contabilidade e Controladoria, v. 5, n. 3, p. 66-82, 2013. Disponivel em: <http://revistas.ufpr.br/rcc/article/viewFile/31269/21744>.

VANTI, N. A. P. ]Da bibliometria à webometria: uma exploração conceitual dos mecanismos utilizados para medir o registro da informação e a difusão do conhecimento. Ciência da Informação, v. 31, n. 2, p. 152-162, 2002. Disponível em: <http://www.scielo br/scielo/scielo.php?pid=s0100-19652002000200016\&script19652002000200016\&script=sc pt=sci_abstract\&tlng=pt. doi: $10.1590 /$ S0100-19652002000200016>.

VOLPATO, G. L. Publicação científica. Botucatu: Santana, 2002. 